\title{
A Study of Tachykinin-Immunoreactive Neurons in Monkey Cerebral Cortex
}

\author{
E. G. Jones, ${ }^{1}$ J. DeFelipe, ${ }^{1, a}$ S. H. C. Hendry, ${ }^{1}$ and J. E. Maggio ${ }^{2}$ \\ 'Department of Anatomy and Neurobiology, University of California, Irvine, California 92717, and 'Department of \\ P.harmacology, Harvard Medical School, Boston, Massachusetts 02115
}

Immunocytochemical methods were used to localize tachykinin-like immunoreactivity within neurons of the monkey cerebral cortex. Three primary antibodies were used: polyclonal antisera raised against fragments of substance $P$ and substance $K$ that excluded the carboxyl termini of these peptides, and a monoclonal antibody that recognized the carboxyl terminus of the tachykinin family. Each antibody stained 2 populations of cortical nonpyramidal neurons: (1) A small number of large, intensely stained cells that give rise to long, coarsely beaded processes; (2) a relatively large number of small, lightly stained cells that are embedded in dense plexuses of stained punctate profiles. The large, dark cells are present in a superficial band that includes layers II and III, and in a deep band that includes layer VI and the subjacent white matter. The smaller, pale cells are present in the middle layers of cortex (layers IV and/or V). Colocalization studies indicate that virtually all the small tachykininimmunoreactive neurons also display GABA immunoreactivity. The larger cells are not GABA-positive, but display both somatostatin-like and neuropeptide $Y$-like immunoreactivity.

The immunocytochemically stained beaded processes and punctate profiles form plexuses that vary in density and laminar distrlbution among different areas of monkey cortex. The coarsely beaded processes form a basic quadrilaminar pattern, with relatively dense plexuses in layers I and $V I$ and in 2 middle layers, usually III and V. However, this pattern varies considerably from area to area.

Electron microscopically, the large cells contain a rich collection of cytoplasmic organelles, particularly Golgi complex, while the small cells contain relatively few organelles. Both types of cells, including large neurons in the white matter, receive symmetric and asymmetric synaptic contacts on their somata and proximal dendrites. The numbers of these axosomatic contacts are low. Virtually all synaptic contacts formed by immunoreactive terminals possess symmetric membrane thickenings. In 2 areas examined in detail (areas 2 and 4), pyramidal cell somata and dendrites are the major targets of the immunoreactive synaptic terminals.

\footnotetext{
Received Apr. 7, 1987; revised July 29, 1987; accepted Sept. 10, 1987.

This work was supported by Grants NS 21377, EY 06432, and NS 22961 from the National Institutes of Health, United States Public Health Service, and by a Sloan Foundation Fellowship to S.H.C.H.

Correspondence should be addressed to Dr. Edward G. Jones at the above address.

"Present address: Unidad de Neuroanatomia, Instituto Cajal, Velazquez, 144, 28006 Madrid, Spain.

Copyright (C) 1988 Society for Neuroscience $0270-6474 / 88 / 041206-19 \$ 02.00 / 0$
}

Until recently, very few neurons of the mammalian cerebral cortex were thought to contain members of the tachykinin family of neuropeptides. Low levels of one tachykinin, substance $P$ (SP), were detected biochemically or by radioimmunoassay in the cerebral cortex of certain species (Brownstein et al., 1976; Kanazawa and Jessell, 1976), but because of the small numbers of cortical somata displaying SP-like immunoreactivity (Ljungdahl et al., 1978; Inagaki et al., 1982) these levels had been attributed to the presence of SP in afferent fibers (Cuello and Kanazawa, 1978; Paxinos et al., 1978) that originate from somata in the dorsal tegmentum of the pons (Sakanaka et al. 1983). Immunoreactivity for other known mammalian tachykinins, such as neuromedin $\mathrm{K}^{\prime}$ (also known as neurokinin $\mathrm{B}$ and neurokinin beta) and substance $\mathrm{K}$ (SK; also known as neurokinin A, neurokinin alpha, and neuromedin L), has not been demonstrated in the cerebral cortex.

Recent reports, however, suggest that SP may be a more significant element in cortical function than previously assumed. Autoradiographic localization of SP binding sites indicates that receptors for the peptide are present in greater numbers and in more areas of cortex than the few SP-immunoreactive afferent fibers previously demonstrated might suggest (Mantyh and Hunt, 1986). Relatively large populations of neurons displaying SPlike immunoreactivity have now been identified in studies of the rat (Loesche et al., 1985; Penny et al., 1986), monkey (Jones and Hendry, 1985), baboon (Beach and McGeer, 1983) and human (Sakamoto et al., 1985) cortex. The SP-positive cells are reportedly nonpyramidal neurons, at least some of which are also immunoreactive for GABA (Jones and Hendry, 1985) or its synthesizing enzyme, glutamic acid decarboxylase (GAD; Penny et al., 1986). Finally, SP is a potent excitatory agent when applied to cortical neurons (Lamour et al., 1983; Jones and Olpe, 1984).

Previous studies of SP localization have used antisera or monoclonal antibodies that recognize the carboxyl terminus of the peptide. Because this part of the peptide sequence is conserved across most members of the tachykinin family (Maggio, 1985), it is not clear whether the observed SP-like immunoreactivity represents the localization of other tachykinins, as well as SP. Antisera that do not cross-react with one another or with those against other tachykinins (J. E. Maggio, unpublished observations) have now been raised against fragments of SP and SK that exclude the carboxyl termini of the 2 peptides. We have used these antisera and a monoclonal antibody that recognizes the carboxyl terminus of both peptides to examine the morphology and synaptic organization of SP- and SK-immunoreactive cortical cells and the coexistence of other putative neu- 
rotransmitters within them. Preliminary reports have appeared (Jones and Hendry, 1985; Jones et al., 1987).

\section{Materials and Methods}

This study was carried out on the brains of 6 cynomolgus monkeys (Macaca fascicularis), weighing $2.75-4.0 \mathrm{~kg}$. None was pretreated with colchicine. The monkeys were deeply anesthetized with intravenous Nembutal and perfused through the heart with $200 \mathrm{ml}$ of $0.1 \mathrm{M}$ phosphate-buffered saline, followed by $3-4$ liters of a fixative solution containing $2 \%$ paraformaldehyde, alone or with $0.1-0.2 \%$ glutaraldehyde in $0.1 \mathrm{M}$ phosphate buffer $(\mathrm{pH} 7.4)$. The brains were removed immediately, cut into blocks, and postfixed in $2 \%$ paraformaldehyde in phosphate buffer for $4-6 \mathrm{hr}$ at $4^{\circ} \mathrm{C}$. Some blocks were then placed in $30 \%$ sucrose in $0.1 \mathrm{M}$ phosphate buffer at $4^{\circ} \mathrm{C}$ until they had sunk and were frozen on dry ice for subsequent sectioning on a sliding microtome. Others were rinsed in $7 \%$ sucrose in $0.1 \mathrm{~m}$ phosphate buffer and sectioned immediately on a Vibratome.

\section{Immunocytochemical methods}

Light microscopy. Three primary antibody reagents were used. Two were polyclonal antisera raised in rabbits, one against fragments of SP from which the carboxyl terminal amino acids had been cleaved ( $R$ 91 P2 ), and the other against similarly prepared fragments of substance $\mathrm{K}$ (R93K-6) (J. E. Maggio, unpublished observations). The cross-reactivities of these antisera with other members of the tachykinin family have been measured by radioimmunoassay. They are, for R91P-2 (SP = $100 \%), 0.02 \%$ with substance $\mathrm{K}$ and $0.01 \%$ with neuromedin $\mathrm{K}$; for R93K-6 $(\mathrm{SK}=100 \%), 2.3 \%$ with neuronedin $\mathrm{K}$ and $0.02 \%$ with SP. The third primary antibody was a rat monoclonal antibody $(\mathrm{NCl} / 34 \mathrm{HL}$, purchased from Sera Labs) that was raised against SP and recognizes the carboxyl terminal sequence common to the tachykinins (Cuello et al., 1979). Frozen sections were cut serially at 10,15 , or $30 \mu \mathrm{m}$, incubated for 24-36 hr in primary antibody (diluted 1:500-1:3000) at $4^{\circ} \mathrm{C}$ and stained either by the peroxidase anti-peroxidase (PAP) method (Sternberger, 1979), using an unlabeled swine anti-rabbit antiserum and rabbit PAP (Dako Corp.), or with the avidin-biotin-peroxidase (ABC) method (Hsu et al., 1981), using a biotinylated goat anti-rabbit IgG or rabbit anti-rat IgG and avidin-biotin-peroxidase complex (Vector). The sections were reacted with $3,3^{\prime}$-diaminobenzidine tetrahydrochloride (DAB; $50 \mathrm{mg} / 100 \mathrm{ml}$ phosphate buffer) and $0.01 \%$ hydrogen peroxide, washed and mounted onto gelatin-subbed slides, treated with chloroform and ethanol to remove lipids and postfixed in $0.1 \%$ osmium tetroxide for 20 min to enhance the $\mathrm{DAB}$ reaction product.

Double-labeling procedures. Sections cut at $4 \mu \mathrm{m}$ on a cryostat were collected on slides and incubated simultaneously in the rat anti-SP monoclonal antibody and in a rabbit anti-GABA, anti-neuropeptide $Y$ (NPY) or anti-somatostatin (SRIF) antiserum. Pairs of adjacent sections were cut and incubated in different combinations of antibodies (e.g., anti-SP plus anti-NPY in one and anti-SP plus anti-SRIF in the other). The 2 primary antibodies were localized simultaneously using affinitypurified fluorescein isothiocyanate (FITC)-conjugated goat anti-rat IgG and rhodamine-conjugated goat anti-rabbit IgG (Cooper Biomedical). The sections were viewed and photographed with a Leitz Dialux fluorescence microscope equipped with fluorescein and rhodamine filter packs.

Electron microscopy. Sections cut at $30 \mu \mathrm{m}$ on a Vibratome were reacted, as above, either by the PAP or by the ABC method, washed in phosphate buffer, and postfixed in $1 \%$ osmium tetroxide for $1 \mathrm{hr}$. They were dehydrated in ethanol, infiltrated with Spurr's resin, and embedded flat between silicone-coated slides and coverslips. The sections were examined under the light microscope and photographed; small pieces of the section, about $4 \mathrm{~mm}^{2}$, were cut out with a razor blade, glued to a cylindrical epoxy blank and cut at 1 or $2 \mu \mathrm{m}$ with glass knives. The semithin sections were collected on plastic slides cast from Spurr's resin, viewed unstained using differential interference microscopy to locate stained profiles, photographed, trimmed, and resectioned at $60-70 \mathrm{~nm}$ on an ultramicrotome (DeFelipe and Fairén, 1982). By this method, cell bodies, processes, and terminal-like profiles could be sequentially identified and sectioned. The thin sections were cut serially and collceted on Formvar-coatcd slot grids; they were stained lightly with lead citrate (Reynolds, 1963) and examined in a Philips EM 300 electron microscope.

Control procedures. A regular series of sections from every block that was sectioned and processed was reacted in monoclonal antibody or polyclonal antisera preadsorbed with $\mathrm{SP}, \mathrm{SK}$, or neuromedin $\mathrm{K}$ at concentrations of $5-50 \mu \mathrm{M}$. Sections were also incubated in primary antibody preadsorbed with $100 \mu \mathrm{M}$ NPY, SRIF, cholecystokinin (CCK) octapeptide, vasoactive intcstinal polypeptide, and dynorphin without reduction in staining. For the double-labeling experiments, sections were incubated in primary reagents that had been preadsorbed with $100 \mu \mathrm{M}$ SP, GABA, NPY, or SRIF or in reagents from which one of the primary antibodies had been omitted or replaced with nonimmune serum of the appropriate species. With preadsorbtion, replacement, or omission of a primary antibody, fluorescent labeling was seen only for the unadsorbed or remaining specific antibody of a pair.

\section{Results}

Immunocytochemical staining with the monoclonal antibody ( $\mathrm{NC1} / 34 \mathrm{HL}$ ) that recognizes the carboxyl terminal sequence will be described first; this will be followed by descriptions of staining produced by antisera directed against fragments of SP (R91P2) and SK (R93K-6) that exclude the carboxyl terminus of each molecule.

\section{Staining with $N C 1 / 34 H L$}

Somata and processes. Neurons and nerve fibers throughout the monkey cerebral cortex are stained immunocytochemically with this antibody. In all cortical areas studied, 2 types of neurons can be distinguished by their morphology and by the character of their staining (Figs. 1, 2). A minority of the cells have large, ovoid somata (maximum diameter, 15-21 $\mu \mathrm{m}$ ) that are very intensely stained and that give rise to long, beaded processes (Fig. 2B). Many of the processes extend for distances of 300$400 \mu \mathrm{m}$, adopt a vertical orientation, and cross several cortical layers. The second type of neuron greatly outnumbers the first; these have small, round somata $(8-10 \mu \mathrm{m}$ in diameter) and are stained lightly. With the exception of an occasional short (5$10-\mu \mathrm{m}$-long) stump emerging from a soma, processes of these neurons are not stained. Instead, the lightly stained cells are always embedded in a dense mass of finely stained, punctate profiles that surround the somata of stained and unstained neurons (Fig. 2A).

Throughout the cortex, the larger, darkly stained somata are found in all layers, but are concentrated in 2 bands that include the deep half of layer VI and the underlying white matter, and layer II and the upper half of layer III (Fig. 1). Although the large cells are seen at more or less regular intervals in other layers, wide stretches of cortex can be found where they are present only in the superficial and deep strata. Even in these strata, their numbers are low.

In the white matter underlying each area of cortex, the large, darkly stained neurons with long processes are particularly evident. Where areas of cortex on 2 faces of a gyrus are separated by narrow stretches of white matter (e.g., in the postcentral gyrus or in the occipital lobe, deep to the calcarine sulcus), an even distribution of SP-positive cells and processes is found. Elsewhere, the darkly stained cells are all found within $500 \mu \mathrm{m}$ of the overlying cortex. Except for an occasional, isolated fiber, staining of somata and processes does not extend in to the corona radiata, internal capsule, or corpus callosum.

The smaller, paler cells are more restricted in their laminar distribution. They are usually concentrated within a stratum in the middle of the cortex that includes the superficial half of layer $\mathrm{V}$ and a portion of layer IV that varies from area to area, but others can be seen in supragranular layers as well. In the primary visual area (area 17), unlike other areas, the middle stratum is more overtly confined to layer IVC (Fig. 1). By contrast, the cells in area 18 are clearly in layer V. A second, periodically 


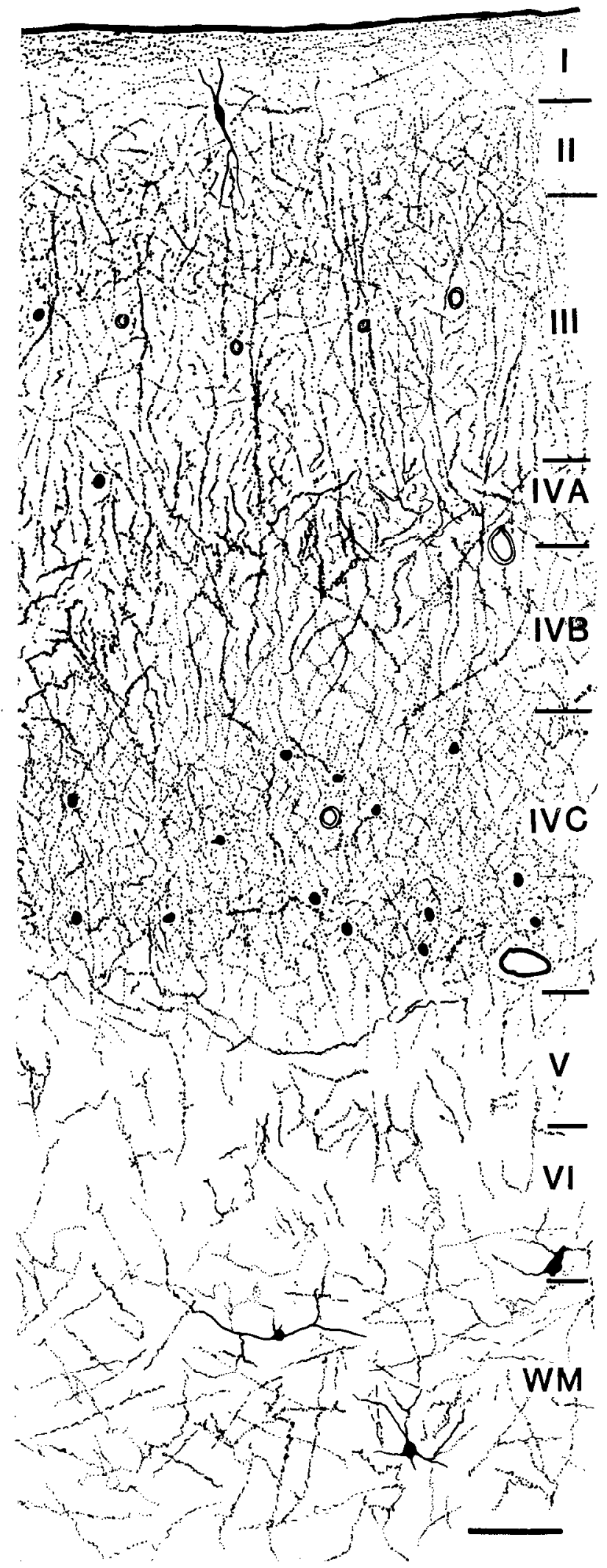

Figure 1. Camera lucida drawing made at low magnification under dark-field illumination, showing the distribution of the 2 kinds of tachykinin-immunoreactive neurons and the immunoreactive plexuses in a section of monkey visual cortex. Layers at right were determined from comparison with an adjacent Nissl-stained section. The set of smaller immunoreactive cells without visible processes is mainly localized in the middle layers (layer $I V C$ of area 17, usually layer $V$ of other areas), intcrupted stratum of small immunoreactive cells and their processes can also be found in layers II and III of area 17 (see Hendry et al., 1988). In other areas, although both types of SPimmunoreactive neurons are distributed unevenly in the horizontal dimension, the pattern shows no regularity and plexus density remains relatively constant.

Immunoreactive plexuses. Large numbers of immunoreactive fibers and punctate elements form dense plexuses in the cortex and underlying white matter (Figs. 1, 3, 4). The laminar positions of these plexuses and the densities of stained elements within them vary from one area to another. In all areas a dense concentration of horizontal fibers is present immediately beneath the pia mater in the outer one-third to one-half of layer I. A second major zone of fiber density is found in the deep half of layer VI and in the subjacent white matter. In the deeper plexus, many fibers run horizontally, but the plexus also gives rise to vertically oriented fibers that ascend into the ovcrlying cortex and commonly reach layer IV. In most areas, a less dense plexus of stained fibers and punctate elements is present in layer II and the upper half of layer III. From this plexus, the density of which varies from area to area, fibers ascend to join the layer I plexus and descend into the deep half of layer III.

The greatest variation in staining among areas of the monkey cortex is found in the middle layers. In some areas (Figs. 3, 4), the fibers in the middle layers consist only of a few vertically oriented processes passing through layers IV and V. By contrast, other areas contain dense plexuses of fibers in layers III and V and concentrations of punctate profiles that lie among the lightly stained somata of layers IV and V. However, since the punctate elements are smaller and stain less intensely than the coarsely beaded fibers, they and the plexus they form are less easily visualized in dark-field microscopy.

The interareal variability in the density of the coarsely beaded fibers can be seen as a progression from frontal areas through parietal and occipital areas into temporal areas (Figs. 3, 4). In prefrontal areas, dense bands occupy most of layer I and the deep half of layer VI, while relatively few, homogeneously distributed fibers are found in the remaining layers. A similar pattern is apparent in the precentral motor area (area 4), but here the superficial plexus is confined to the outcr half of layer I and a hint of an additional plexus is seen in layer II and the superficial part of layer III. In areas 1 and 2 of the first somatic sensory cortex (SI), the pattern and density of fibers is the same as that seen in area 4 , while in area $3 \mathrm{~b}$ of SI, the overall density of fibers is greater and the layer II plexus is more distinct.

Beginning with areas 5 and 7 of the parietal lobe and continuing into the areas of the occipital lobe, 4 fiber plexuses can be distinguished. These include the usual plexuses in layer I and layer VI, plus dense, wide plexuses in the deeper half of layers III and V. Both layers II and IV contain few intensely stained, beaded fibers. A similar, low-fiber density is also seen for each sublamina of layer IV (layers IVA, IVB and IVC) in area 17 and throughout layer IV of the adjacent area 18 . However, in both areas, very dense collections of small, punctate, immunostained elements fill layers IVA and IVC of area 17 and the deep half of layer IV of area 18.

The quadrilaminar pattern of stained plexuses is also apparent in the more lateral areas of temporal cortex. However, in pro-

while the larger, process-bearing cells are found mainly at superficial and deep levels. Bar, $100 \mu \mathrm{m}$. 


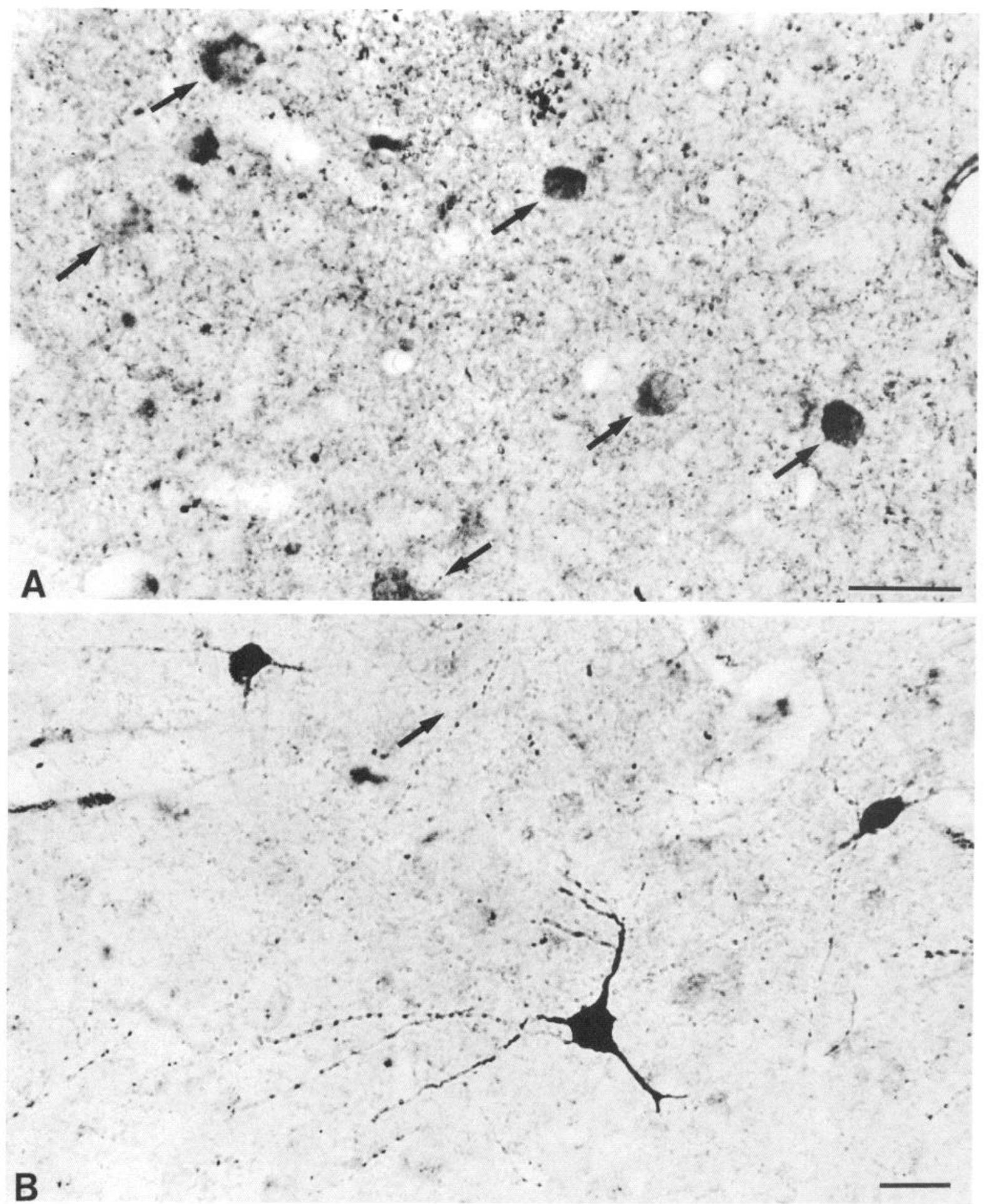

Figure 2. A, The smaller, less intensely stained tachykinin-immunoreactive neurons (arrows) of the middle layers of area 17 , characteristically embedded in the dense mass of immunoreactive punctate elements. Stained with antibody NC1/34HL. $B$, The large, intensely stained, processbearing immunoreactive cells of layer VI and the subcortical white matter of area 17. Arrow indicates an ascending process. Stained with antibody $\mathrm{NC1} / 34 \mathrm{HL}$. Bars, $20 \mu \mathrm{m}$.

gressing medially toward the hippocampal formation, the 2 superficial plexuses widen and fuse to form a single stained band. Similarly, the 2 deep plexuses tend to become continuous, leaving only layer IV without a dense concentration of coarse, beaded fibers. In the more medial areas of the temporal cortex, fewer fibers are stained in layer IV, but they are particularly thick and coarsely beaded.

These interareal variations in the density and distribution of the plexuses are not correlated with any obvious differences in the numbers and distributions of the larger, darkly stained cell 

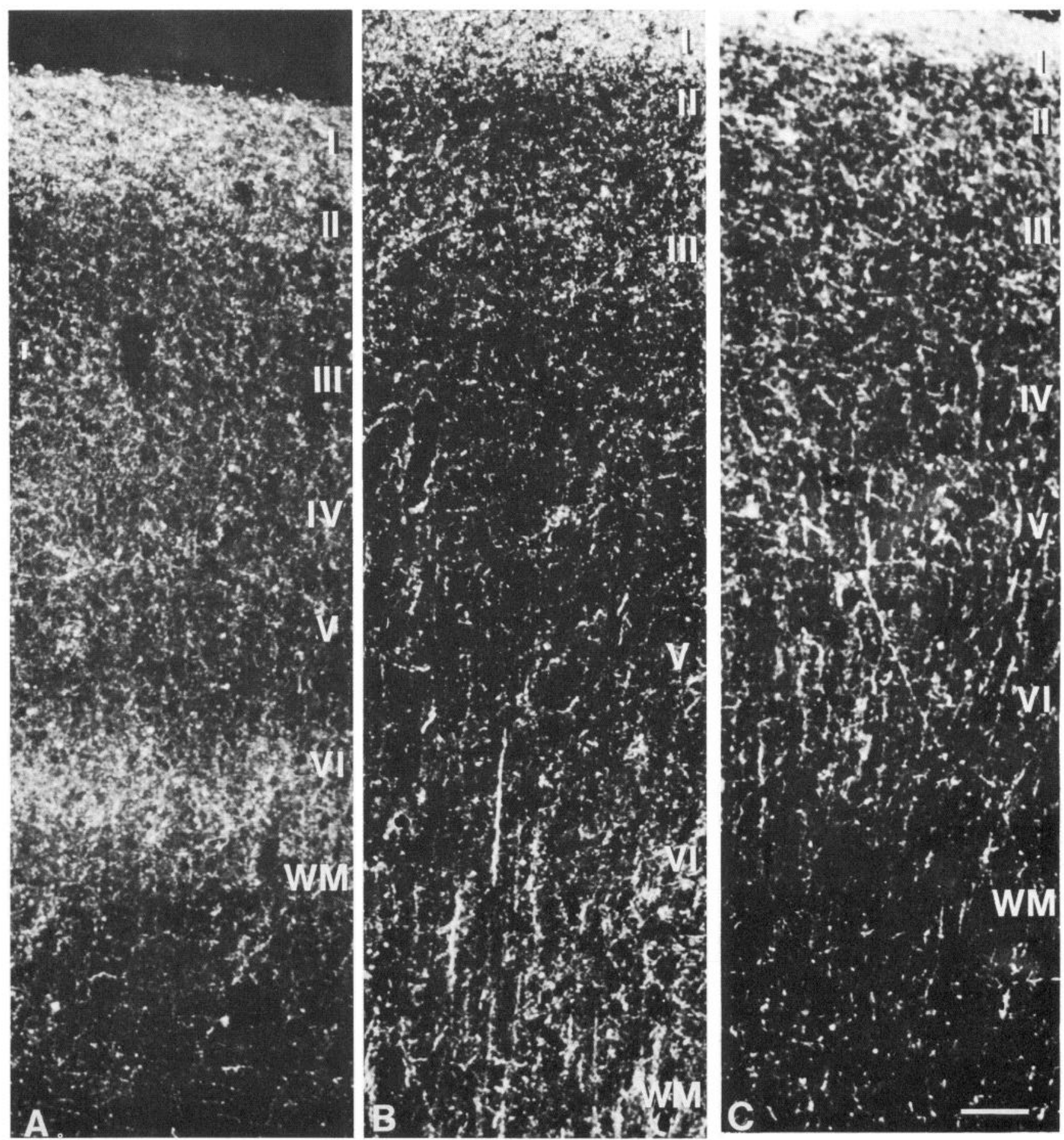

Figure 3. Dark-field photomicrographs of the different patterns of tachykinin immunoreactive plexuses in lateral frontal cortex $(A)$, area $4(B)$ and areas 1 and $2(C)$. Stained with antibody NC1/34HL. Bar, $500 \mu \mathrm{m}$.

bodies, even among areas of the sensorimotor and parietal association cortex, where clear differences in plexuses are found. Interareal variations are more apparent in the density of the smaller, palely stained cell bodies, with the middle layers in areas of the frontal and occipital cortex containing a larger number, and the same layers in parietal and temporal cortex containing many fewer.

Control experiments. The staining of large and small somata, coarsely beaded processes, and small, punctate profiles was re- duced by the preadsorbtion of $\mathrm{NC1} / 34 \mathrm{HL}$ with synthetic SP at a concentration of $5 \mu \mathrm{M}$ in diluted (1:1000) antibody, and was blocked at concentrations of peptide greater than $10 \mu \mathrm{M}$. Staining with $\mathrm{NC1} / 34 \mathrm{HL}$ was also blocked by concentrations of SK and neuromedin $\mathrm{K}$ only slightly higher (15-20 $\mu \mathrm{M}$ ) than those found effective with SP. The antibody, therefore, clearly recognizes and is adsorbed by the carboxyl terminus of each tachykinin. Similar findings, in which immunocytochemical staining with $\mathrm{NC1} / 34 \mathrm{HL}$ was blocked by preadsorbtion with several members 

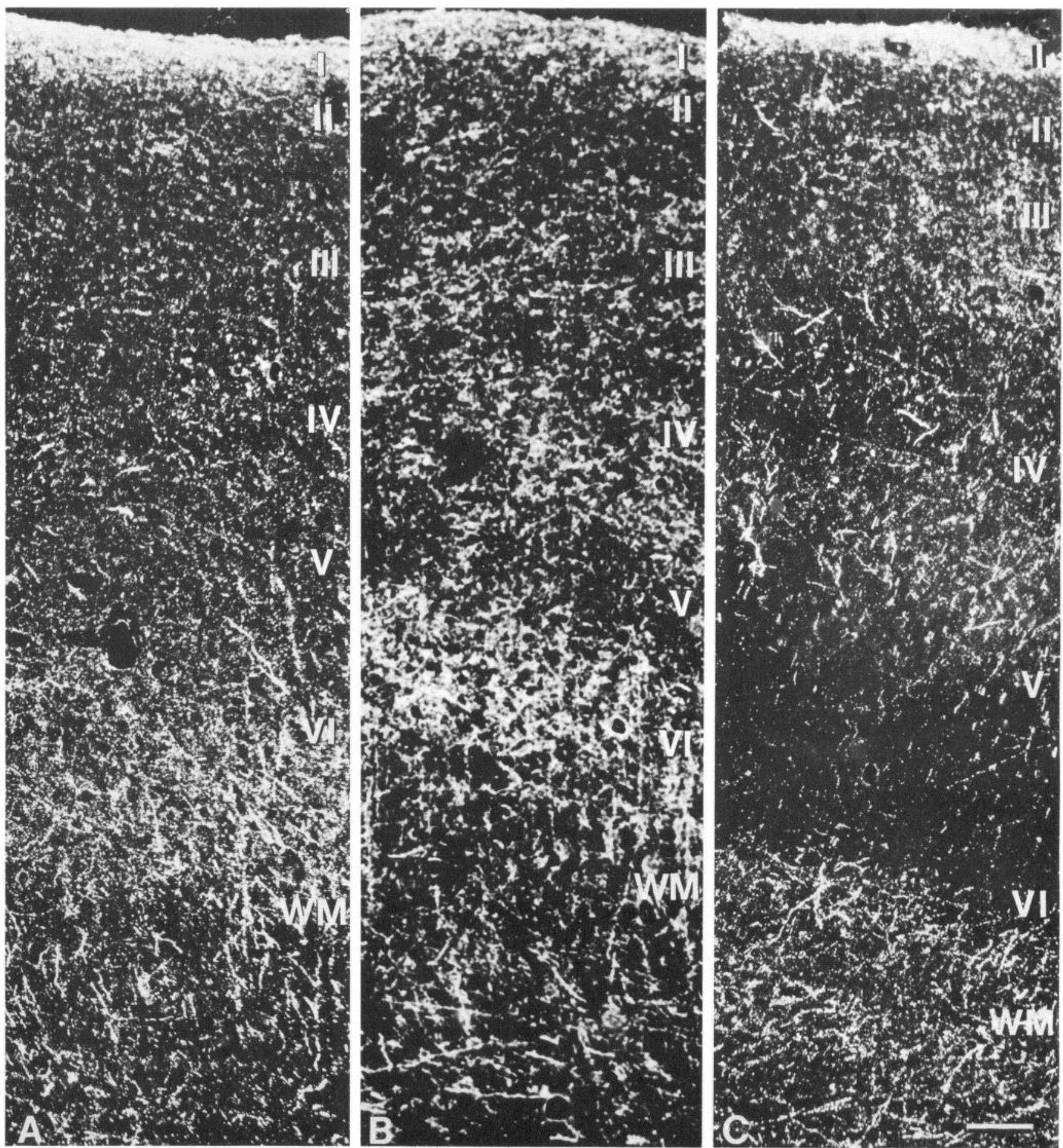

Figure 4. Further patterns of tachykinin-immunoreactive plexuses in area $7(A)$, inferior temporal gyrus $(B)$, and area $17(C)$. Stained with antibody $\mathrm{NCl} / 34 \mathrm{HL}$. Dark-field photomicrographs of area $17(C)$ do not clearly reveal the fine punctate elements in the middle layers (cf. Fig. 1). Bar, $500 \mu \mathrm{m}$

of the tachykinin family, have been reported previously (Sundler et al., 1985).

\section{Staining with R91P-2 and R93K-6}

We used antisera raised against fragments of SP (R91P-2) and SK (R93K-6) that excluded the carboxyl terminus of each molecule. The staining in each case was comparable to but lighter than that achieved with the monoclonal antibody $\mathrm{NC1} / 34 \mathrm{HL}$.
Antibody R91P-2 stains the large, intensely immunoreactive somata and coarsely beaded fibers in each area of cortex and also the lightly immunoreactive somata and small, punctate elements that occupy principally the middle layers of cortex. The staining is, in both cases, weaker than that with NC1/34HL. Quantitative analyses indicate that the number of large, intensely stained somata in $500 \mu \mathrm{m}$-wide columns extending through the thickness of each area and into the white matter for $400 \mu \mathrm{m}$ 

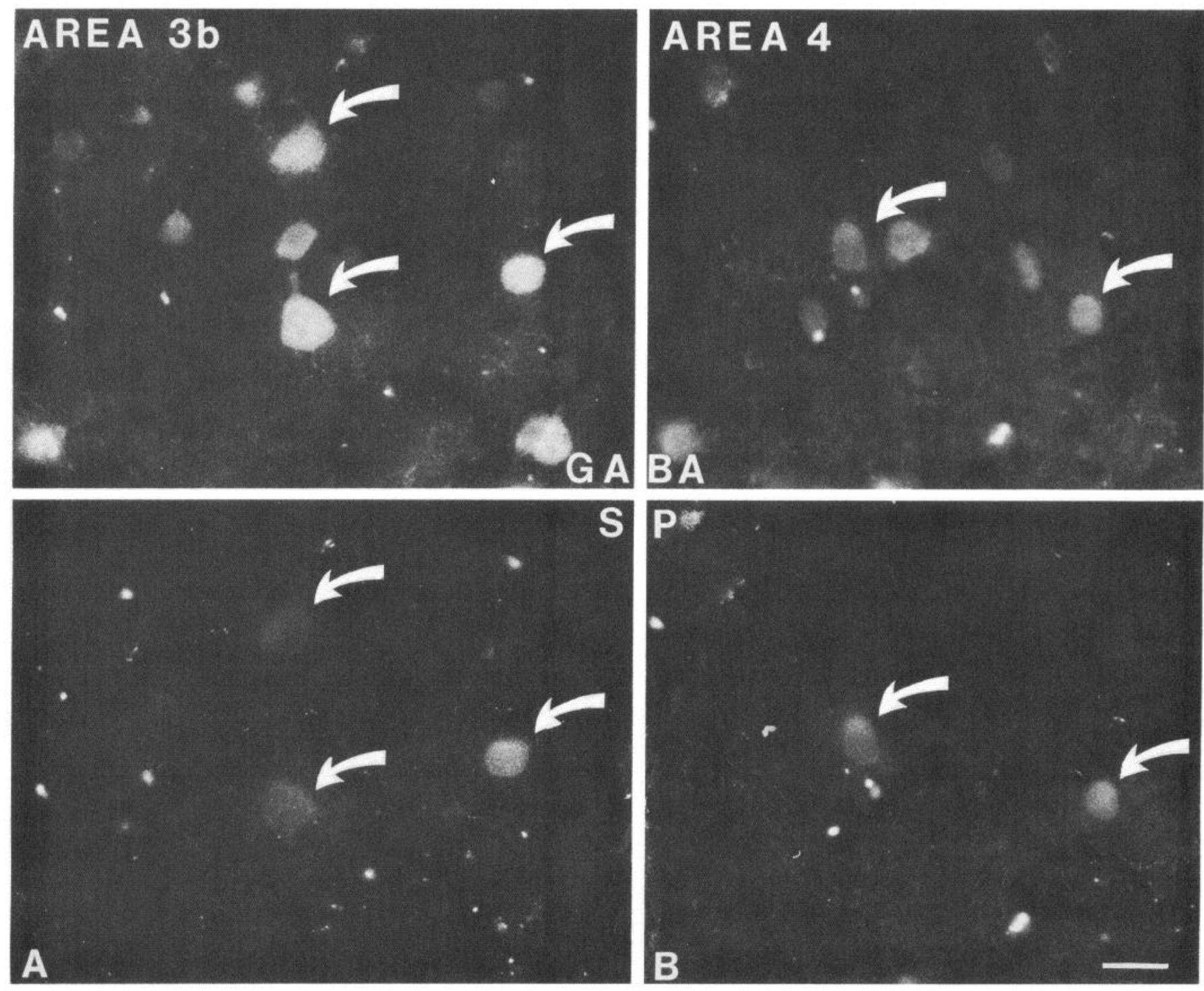

Figure 5. Paired fluorescence micrographs from the same field showing colocalization of tachykinin-like immunoreactivity $(S P)$ with GABA immunoreactivity in certain neurons (arrows) of the middle layers from areas $3 \mathrm{~b}$ (left pair, $A)$ and 4 (right pair, B). Note that only a proportion of the GABA neurons show tachykinin-like immunoreactivity. Bar, $10 \mu \mathrm{m}$.

is approximately half the number stained with NC1/34HL. A prominent density of processes is found in layer VI, near the border with the white matter, but otherwise the positions of plexuses in each area are discerned with difficulty.

Demonstration of the small, lightly stained cell population depends critically on the concentration of the antiserum. At antiserum dilutions greater than $1: 2500$, the staining is too light to detect these neuronal elements in any area of cortex, and at dilutions less than $1: 1000$, the increase in nonspecific staining of somata and neuropil masks their appearance.

In every major respect, the staining with the anti-SK antiserum, R93K-6, is identical to that seen with the anti-SP antiserum, R91P-2. All of the elements stained with NC1/34HL are stained with R93K-6, but the immunoreactive somata and processes are again fewer in number and the plexuses are difficult to discern. In $500 \mu \mathrm{m}$-wide columns, the number of large cells intensely stained for SK by R93K-6 is less than half the number stained for tachykinins by $\mathrm{NC1} / 34 \mathrm{HL}$. When adjacent sections stained with the 3 antibodies are compared, the number of intensely stained cells in sections processed with R91P-2 is equal to that in sections processed with R93K-6, but the two, together, make up less than the number in sections stained with $\mathrm{NCl}$ / $34 \mathrm{HL}$. The small, stained somata and accompanying punctate elements can be detected with a wider range of R93K-6 dilutions (1:500-1:3000) than is possible with R91P-2.

All staining with the anti-SP antiserum R91P-2 is blocked by preadsorption with synthetic SP at concentrations greater than $10 \mu \mathrm{M}$ in diluted $(1: 1500)$ antiserum. By contrast, staining remains after adsorption with either synthetic SK or synthetic neuromedin $\mathrm{K}$ at concentrations of $50 \mu \mathrm{M}$. All staining with the anti-SK antiserum R93K-6 (diluted 1:1500) is blocked by preadsorption with synthetic SK $(10 \mu \mathrm{M})$ but not by $50 \mu \mathrm{M}$ SP or neuromedin $\mathrm{K}$.

\section{Colocalization experiments}

Experiments in which the monoclonal antibody, NC1/34HL, was used to localize tachykinin immunoreactivity reveal that the 2 populations of neurons stained with this antibody can be 

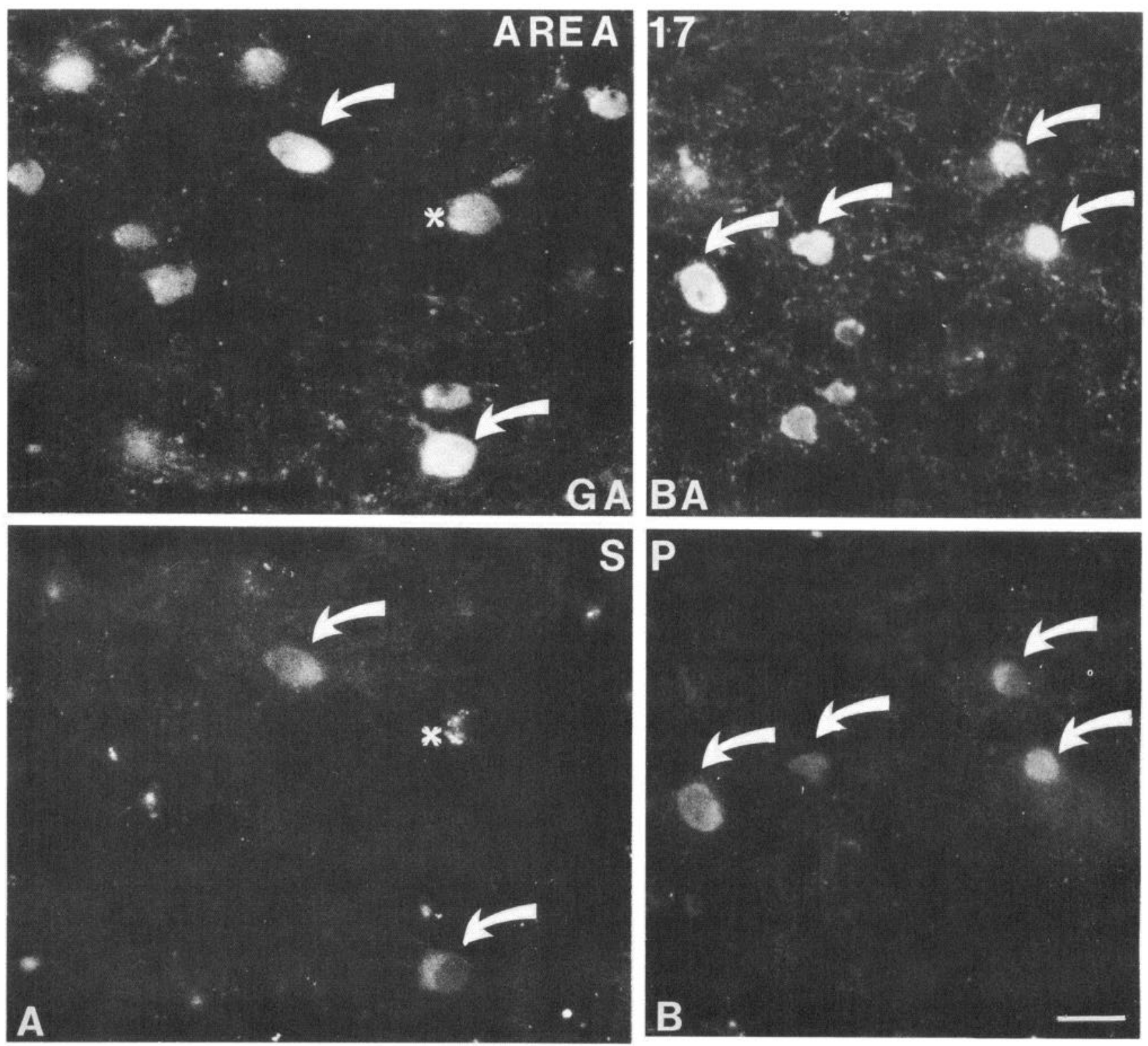

Figure 6. Paired fluorescence micrographs $(A, B)$ showing colocalization of GABA- and tachykinin-like immunoreactivity in certain neurons from 2 fields in area 17. Fluorescent dots in single-stained neuron (asterisk) at right of $A$ are lipofuscin granules. Bar, $10 \mu \mathrm{m}$.

distinguished from each another by the coexistence of immunoreactivity for other neuroactive substances. In any microscopic field covering the middle layers of a cortical area, a large population of GABA-immunoreactive neurons is found (Hendry et al., 1987); within that population, a moderate percentage (counted, on average, as $30 \%$ ) is also stained with $\mathrm{NC1} / 34 \mathrm{HL}$. All of the small, pale, tachykinin-immunoreactive cells are GABA-positive (Figs. 5, 6), but they are scattered among a much larger group of neurons of the same size and shape that are stained for GABA only. Among the GABA-positive neurons that display no tachykinin-like immunoreactivity are the many large neurons with somata $15-25 \mu \mathrm{m}$ in diameter.

Very few of the larger, intensely stained tachykinin cells display GABA immunoreactivity. Counts of over 500 of these cells reveal only 7 that are also GABA-positive. Instead, the larger tachykinin-positive cells and the processes they give off often, though not invariably, display NPY- and SRIF-like immuno- reactivity (Figs. 7,8 ). In sections reacted with $\mathrm{NCl} / 34 \mathrm{HL}$ and with antiserum to either NPY or SRIF, approximately $5 \%$ of both the total NPY-immunoreactive population and the total SRIF-immunoreactive cell population are also tachykinin-positive (Fig. 7). Neurons displaying SP and NPY or SP and SRIF coexistence are found widely scattered throughout the cortex, but are most numerous in the subcortical white matter. No member of the lightly stained population of small tachykininpositive neurons in the middle layers of cortex displays SRIFor NPY-like immunoreactivity.

The numerous, lightly stained punctate profiles found in association with the lightly immunoreactive cells also display GABA immunoreactivity. By contrast, the long, coarsely beaded tachykinin-positive processes are rarely stained for GABA but often display NPY- or SRIF-immunoreactivity instead (Fig. 7). These processes, however, make up only a small proportion of the fibers stained for either NPY or SRIF. 

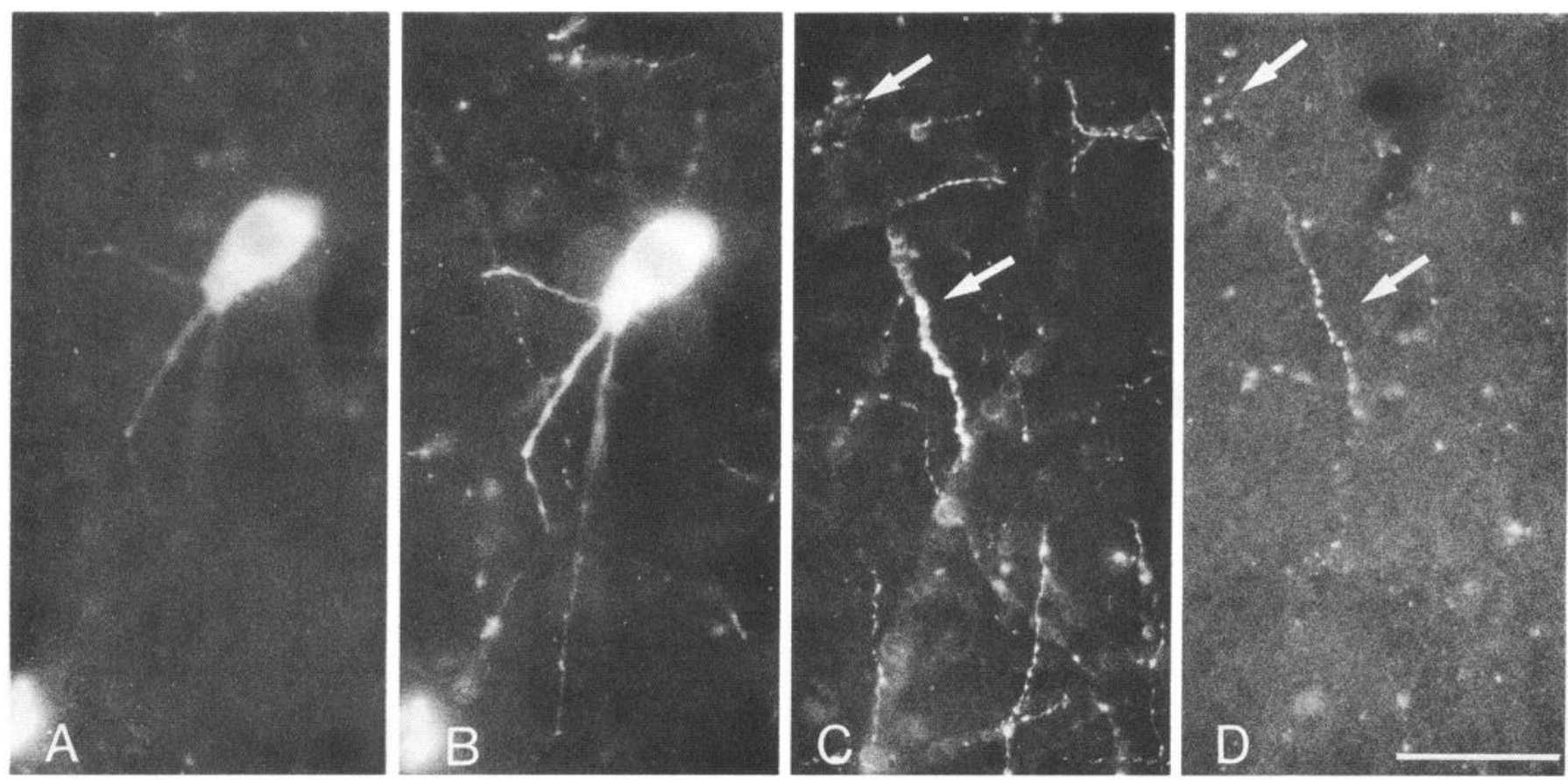

Figure 7. Paired fluorescent micrographs showing colocalization of tachykinin-like immunoreactivity $(A)$ with NPY-like immunoreactivity $(B)$ in a neuron of layer VI in area 4. In the same layer and area, NPY-like $(C)$ and tachykinin-like $(D)$ immunoreactivities are colocalized within long, beaded processes (arrows). Bar, $100 \mu \mathrm{m}$.
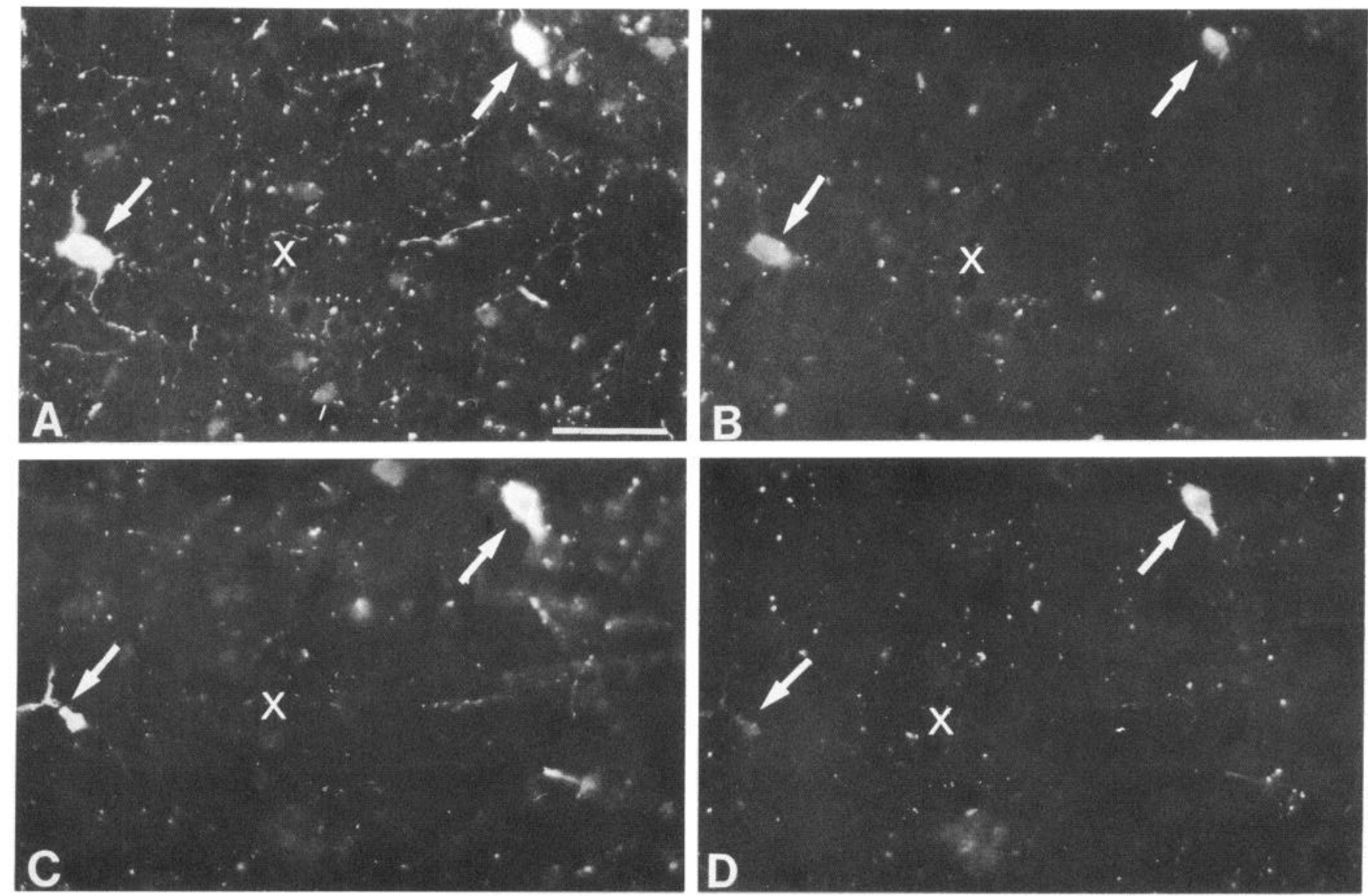

Figure 8. $A-D$, Paired fluorescence micrographs $(A, B$ and $C, D)$ from the same fields in 2 adjacent 4- $\mu$ m-thick sections. One section was stained for NPY- $(A)$ and tachykinin-like immunoreactivities $(B)$ while the adjacent section was stained for SRIF- $(C)$ and tachykinin-like $(D)$ immunoreactivities. All 3 immunoreactivities are found in 2 neurons (arrows) from the white matter beneath area $3 \mathrm{~b}$. Bar, $100 \mu \mathrm{m}$. 
When adjacent pairs of $4-\mu \mathrm{m}$-thick sections are incubated in R91P-2 (for SP) and R93K-6 (for SK), cell bodies stained for SP are usually costained for SK. Of 217 somata displaying SPlike immunoreactivity in sensorimotor, visual, and temporal areas of monkey cortex, over $90 \%$ (197) are found to display SK-like immunoreactivity in the adjacent section.

\section{Electron-microscopic observations}

The monoclonal antibody $\mathrm{NCl} / 34 \mathrm{HL}$ was used to stain Vibratome sections for subsequent electron-microscopic analysis. In semithin sections cut from this material, the same stained neuronal elements can be detected as are found in the frozen sections. Although the osmium intensification of the immunocytochemical reaction product reduces the difference in staining between the 2 types of immunoreactive somata, they can still be distinguished by their sizes, laminar distributions, and the presence or absence of stained processes. Both coarsely beaded processes and terminal-like, punctate structures are identifiable in this material; the latter are found adjacent to structures that can be identified as the somata and proximal dendrites of pyramidal cells (Fig. 9). Examples of each type of stained soma and process were selected from the semithin sections and resectioned for electron-microscopic analysis.

In addition to neurons examined in isolated thin sections, 11 stained neurons were studied in serially collected thin sections cut from continuous series of 5-10 semithin sections (for a total of 75-150 thin sections). The sections were cut from cytoarchitectonic areas 4 or 2 or from the white matter underlying these areas; the neurons included 3 from the white matter and 3 from the cortex proper that were large, intensely stained, and process-bearing, plus 5 from the cortex that were smaller, more lightly stained, and devoid of stained processes. The latter were selected exclusively from the middle layers of cortex.

The 2 types of immunoreactive neurons show distinct differences in the quantity of organelles that they contain. The larger, more intensely stained type is packed with organelles and is particularly rich in Golgi complex and endoplasmic reticulum (Figs. 10, 11). Along the surfaces of these organelles and of the mitochondria, the electron-dense reaction product forms the typical uniform coating commonly seen with peroxidase localization of a cytoplasmic antigen. In addition, the reaction product forms clumps that appear to be associated with aggregations of Golgi membranes at low magnification and, at high magnification, are found to outline large numbers of dense-core vesicles and other vesicular elements of the Golgi complex (Fig. 11).

By comparison, a lower density of cytoplasmic organelles is found in the smaller, less intensely stained somata (Fig. 12). The cytoplasm of these cells is pale and contains relatively little Golgi complex, a few short cisternae of rough endoplasmic reticulum, and scattered ribosomal rosettes. In these cells, immunocytochemical reaction product is distributed uniformly along the surfaces of cytoplasmic organelles.

Both types of cells receive symmetric and asymmetric contacts on their somata and proximal dendrites, but the numbers of contacts on the somata are particularly small, with only one or 2 synapses found within any long series of thin sections. One large, intensely stained soma that was almost completely reconstructed from a series of thin sections received only 2 axosomatic contacts. Two other somata in the white matter that were partially reconstructed received no synaptic contacts in the series of sections that were cut. Typically, in the cortex proper,

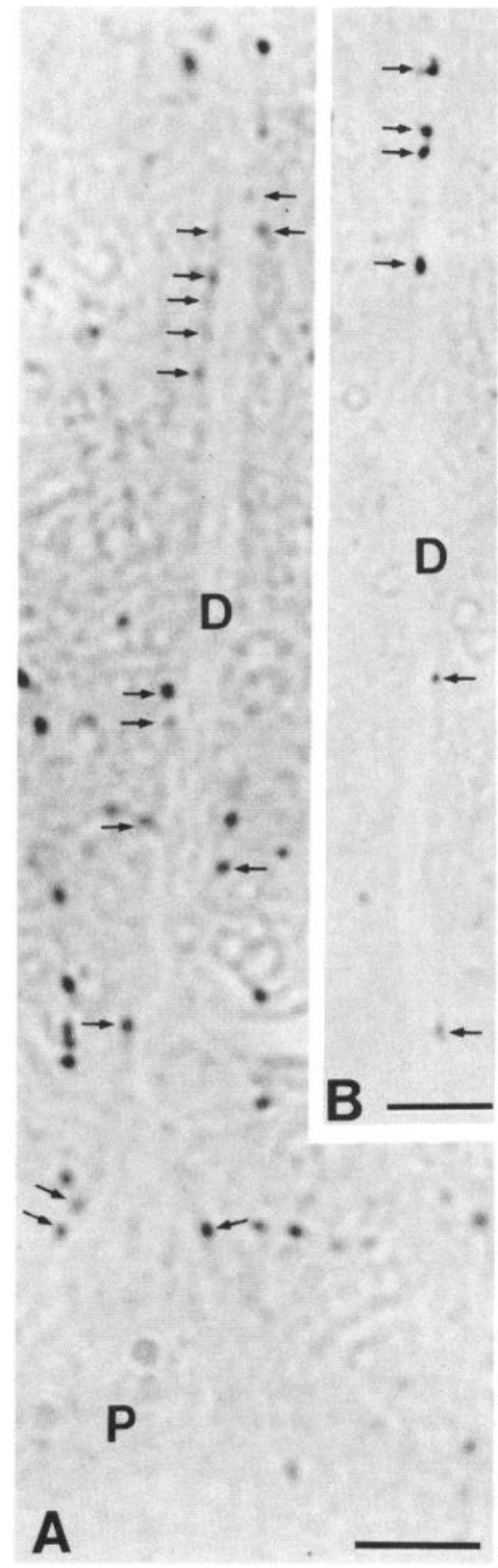

Figure 9. Plastic semithin sections cut from Vibratome sections stained immunocytochemically for tachykinins with NC1/34HL. Small arrows indicate immunoreactive punctate profiles applied to the surfaces of a pyramidal $(P)$ neuron soma and to an apical dendrite $(D)$ in layer III of area 4 . All of these puncta proved to be making synaptic contacts on the underlying profile when subsequently resectioned and examined electron-microscopically. Bars, $10 \mu \mathrm{m}$.

1-3 axosomatic synapses were found in each series of thin sections through this type of neuron. This number is low in comparison with that found on other, nonimmunoreactive cortical nonpyramidal cells.

Immunoreactive dendrites in both the cortex and white matter present no unusual features that distinguish them from other dendrites. The typical organelles are present, and in both sites the dendrites receive synapses, although the number is extremely small (Figs. $10, C, D ; 11 D ; 12 D$ ), especially on cells in the white matter (Fig. 11D).

Punctate immunoreactive profiles seen adjacent to neuronal 

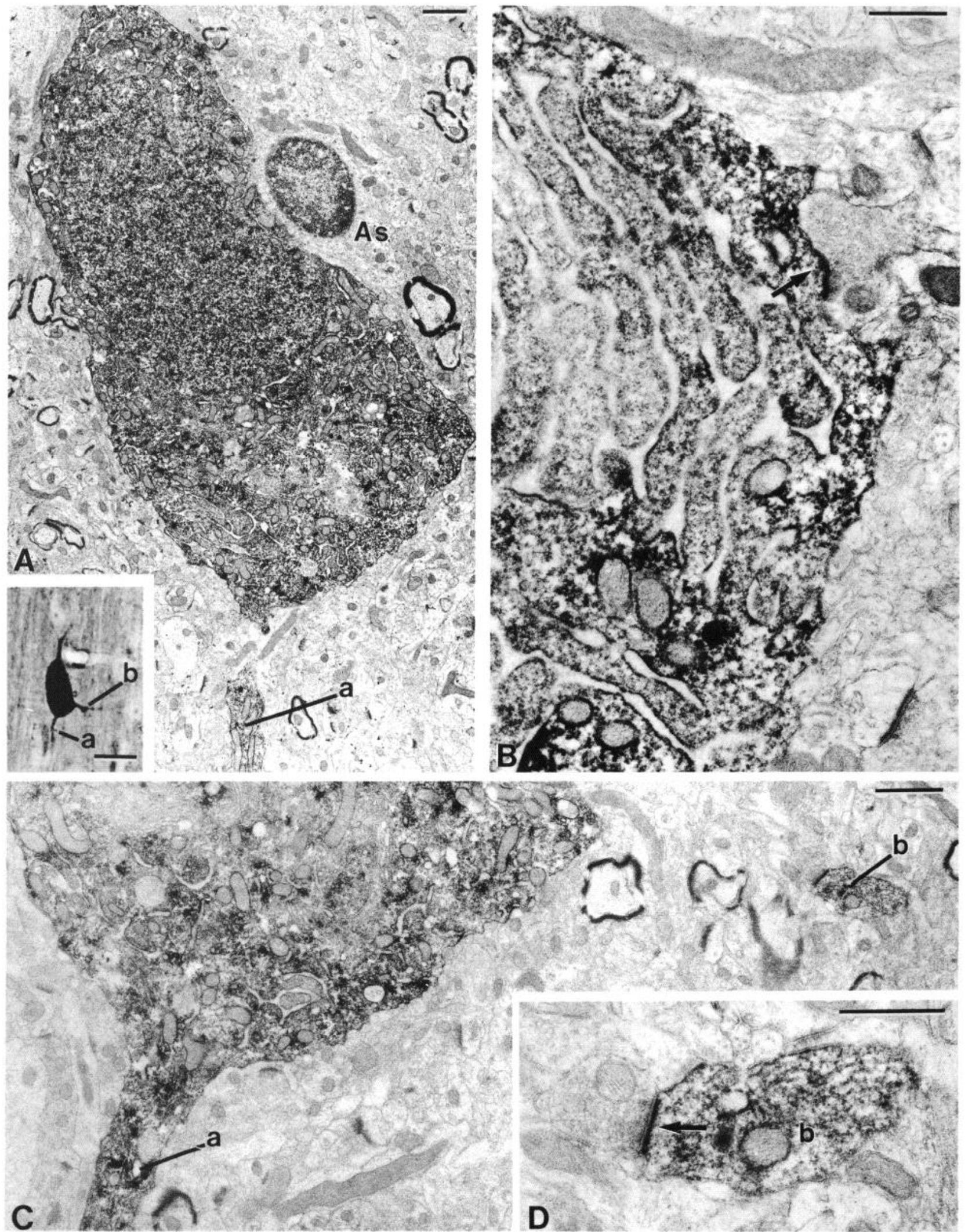

Figure 10. A large, intensely stained immunoreactive neuron from layer II of area 2. Photomicrograph of a semithin plastic section shows the soma and 2 processes of this neuron (inset, left). $A-D$, Electron micrographs from a series of thin sections cut from the semithin section shown in the inset. A small number of nonimmunoreactive, symmetric (arrow in $B$ ) and asymmetric (arrow in $D$ ) synapses were on the soma and processes of the immunoreactive cell. $D$ is a higher-magnification electron micrograph of the process $(b)$ shown in $C$. As, astrocyte. Bars: $1 \mu \mathrm{m}(A, C) ; 0.5$ $\mu \mathrm{m}(B, D), 50 \mu \mathrm{m}$ (inset). 

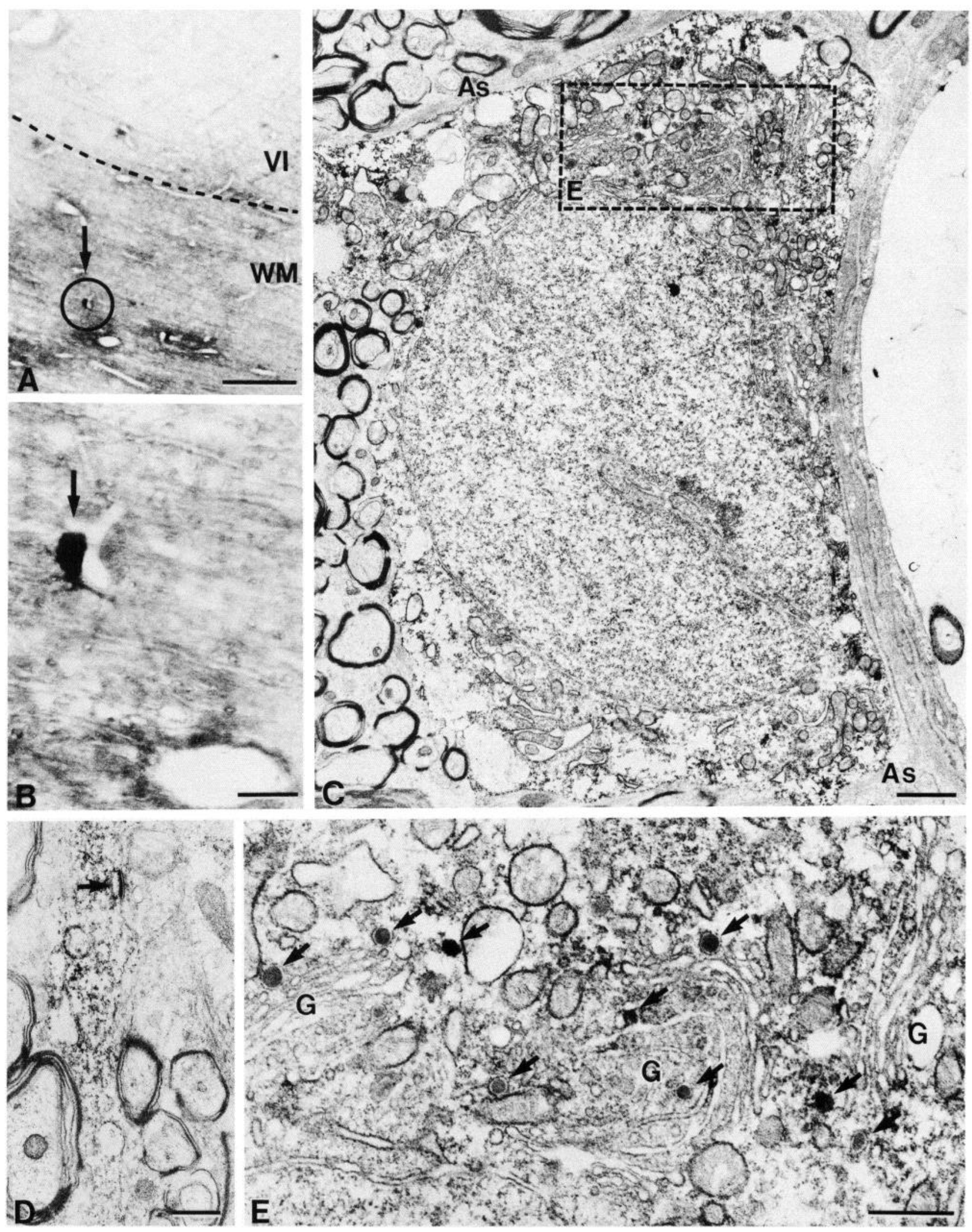

Figure 11. A large, intensely stained immunoreactive neuron from the white matter $(W M)$ beneath area 4 (arrow, $A, B)$, resectioned for electron microscopy $(C-E)$. $C$ shows the cell closely applied to the adjoining blood vessel. The area outlined by the rectangle is enlarged in $E$, which shows reaction product associated with dense-core vesicles (arrows) and part of the extensive Golgi complex $(G)$. $D$ shows an asymmetric synapse (arrow) from a unstained terminal on one of the processes of this cell in the white matter. Bars: $1 \mathrm{~mm}(A) ; 100 \mu \mathrm{m}(B) ; 1 \mu \mathrm{m}(C) ; 0.5 \mu \mathrm{m}(D, E)$. 

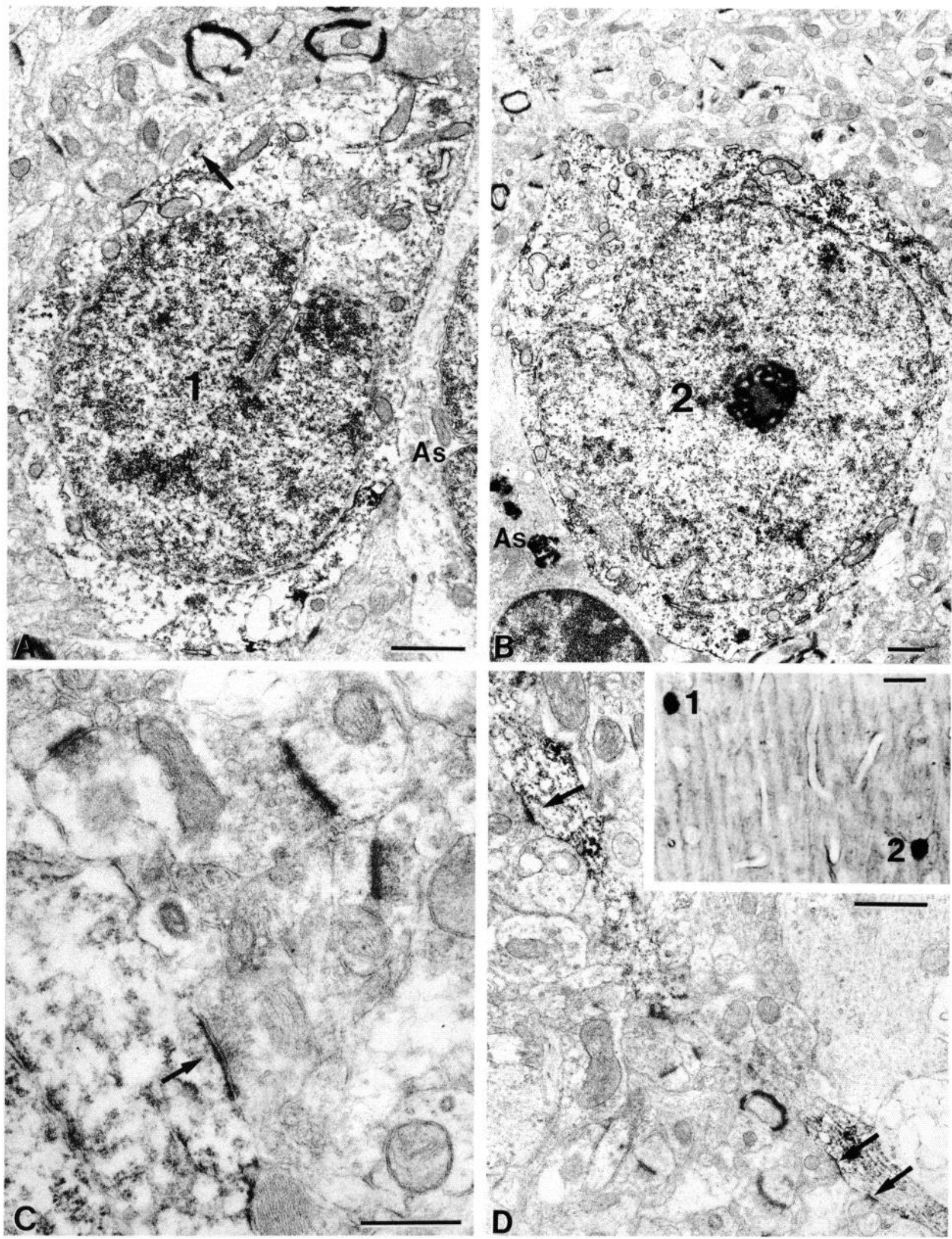

Figure 12. Small neurons from layer III of area 4 (inset, 1, 2). Before osmication, these were categorized as the pale-staining type. In comparison with the large, dark neurons in Figs. 9 and 10, these neurons show a paucity of cytoplasmic organelles at the electron-microscopic level $(A, B)$. Cell soma 1 receives a symmetric synapse in $A$ (arrow) from an unstained terminal and cell soma 2 receives an asymmetric synapse in another section (C, arrow). In $D, 3$ synapses (arrows) are seen on one of the processes of cell 2. Bars: $1 \mu \mathrm{m}(A, B) ; 0.5 \mu \mathrm{m}(C, D) ; 10 \mu \mathrm{m}$ (inset). 


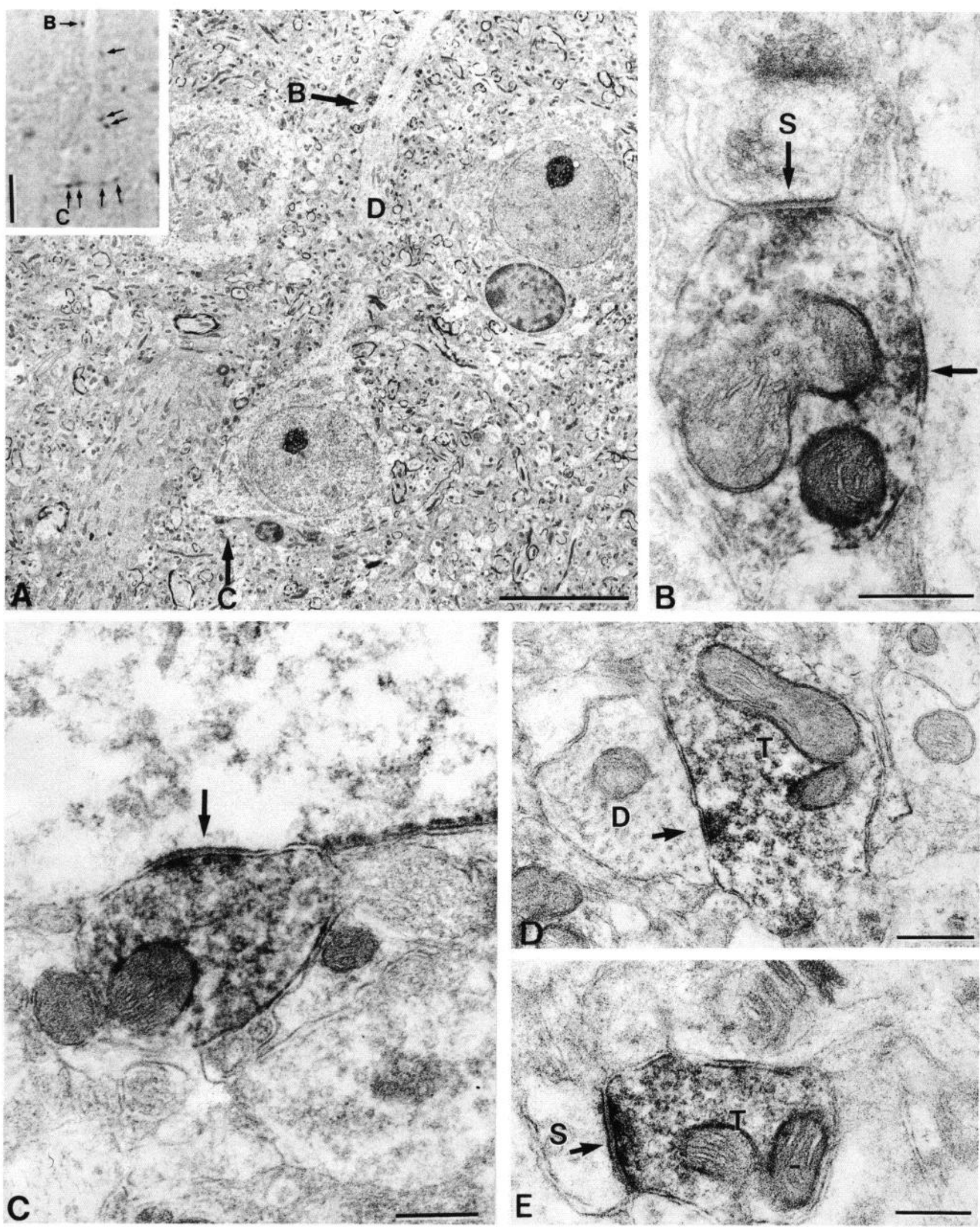

Figure 13. A-C, A small pyramidal neuron from layer II of area 2 with closely approximated immunoreactive puncta (small arrows, inset) that proved on thin sectioning to be contacting the neuron. Two of these contacts are shown at low magnification in $A$ and at higher magnification in $B$ and $C$. The same terminal is shown in $B$ and $C$ from 2 sections of the series. The synaptic contacts (larger arrows) are symmetrical. $B$, The immunostained terminal is making contacts on both the apical dendrite $(D)$ and an adjacent dendritic spine $(S)$. D, $E$, Tachykinin-immunoreactive terminals $(T)$ making symmetric contacts (arrows) on a nonimmunoreactive dendrite $(D)$ and on a dendritic spine $(S)$. Bars: $10 \mu \mathrm{m}(A) ; 0.25 \mu \mathrm{m}$ $(B-E) ; 10 \mathrm{~mm}$ (inset). 

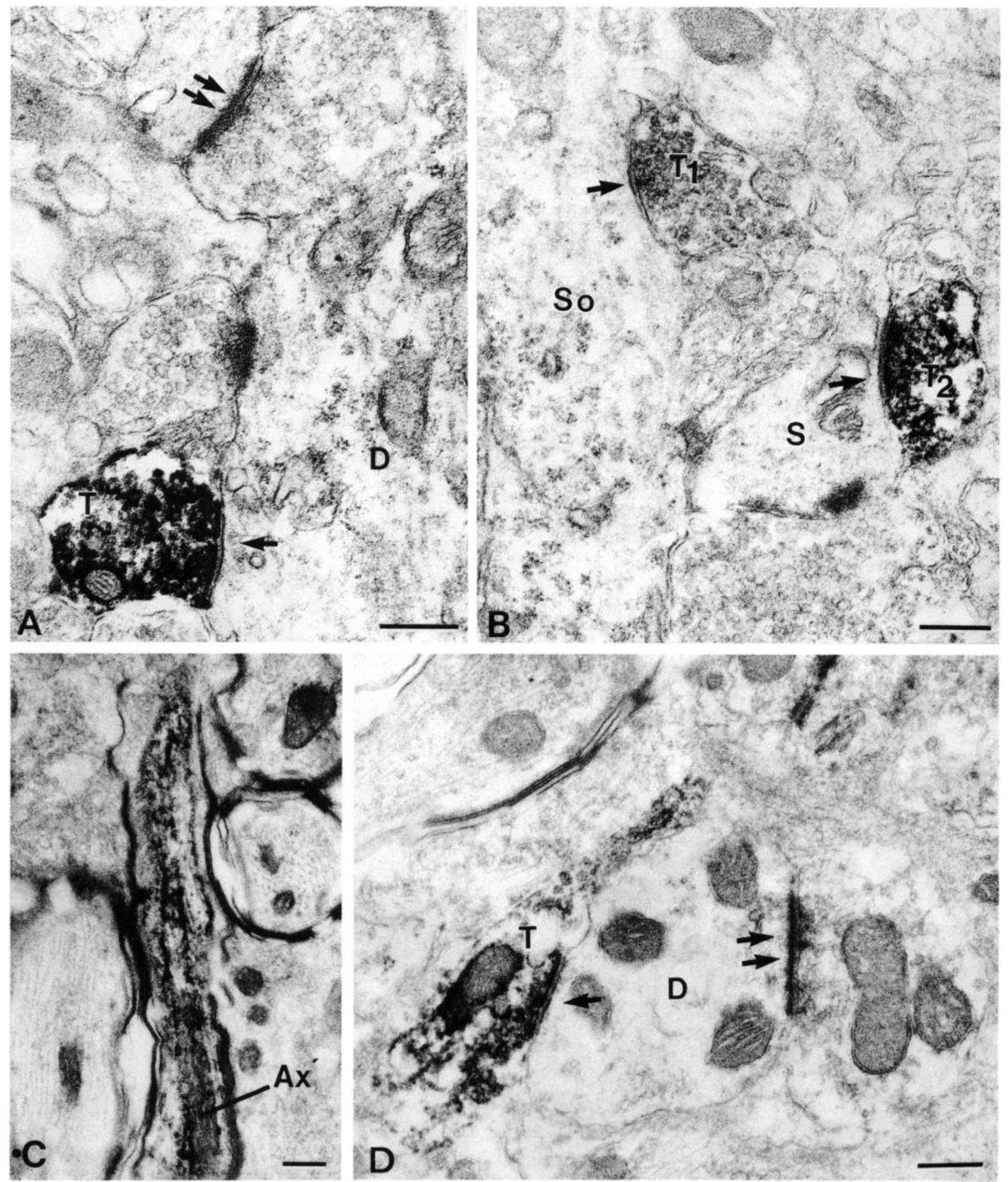

Figure 14. A, B, Immunoreactive terminals $(T)$ making symmetrical synaptic contacts (single arrows) on a large dendrite $(D)$ and a neuronal soma $(S o)$ in layer III of area 4. $C, D$, An immunoreactive, small, myelinated axon $(A x)$ from layer III of area 4 was traced through a series of thin sections and eventually gave rise to the immunoreactive terminal $(T)$ that made a symmetrical contact (single arrow) on a small dendrite $(D)$. This dendrite also received an asymmetrical contact (double arrows) from a nonimmunoreactive terminal. Bars, $0.25 \mu \mathrm{m}$.

somata and dendrites in semithin sections (Fig. 9) proved on thin sectioning to be tachykinin-positive axon terminals (Figs. $13,14)$. Three hundred and twelve immunoreactive terminal boutons were examined serially and made 348 identifiable syn- aptic contacts, all but 2 of which possessed symmetric membrane thickenings (Figs. 13, 14). The stained terminals formed synaptic contacts on neuronal somata, large proximal dendrites, finer (presumably more distal) dendrites, and dendritic spines 
(Figs. 13, 14). Occasionally, a single terminal made more than one synaptic contact, contacting different kinds of postsynaptic profile (Fig. 13C), e.g., a spine and a dendritic shaft. One terminal was seen to arise from a myelinated immunoreactive axon (Fig. 14).

As is seen in Table 1, pyramidal cell somata and dendrites are major targets of tachykinin-immunoreactive synaptic terminals in areas 4 and 2. The synapscs onto pyramidal cell dendrites and spines account for almost half of the commonly observed contacts, with the other synapses occurring on processes of unidentified cell types, many of which may also be pyramidal cells. Of this sample of 348 synapses, only 10 were found on dendrites or somata of positively identified nonpyramidal cells.

Each of the stained terminals found to form synaptic contacts in the electron microscope was identified first with the light microscope by examining semithin plastic sections. In every case in which a terminal was found apposed to a cell body or large process, a synaptic contact between the 2 elements was discovered (e.g., Fig. 13). We used this strong correlation between light-microscopic prediction and electron-microscopic observation to make a provisional survey of the targets of stained terminals as seen in the light microscope. The clearest finding is that within a single semithin section, a few pyramidal cell somata and proximal dendrites are surrounded by stained terminals, while the somata and dendrites of most adjacent pyramidal cells have very few or no terminals around them. (In reconstructions through $10-20$ semithin sections, the vast majority of pyramidal cells have no more than 2 or 3 stained terminals contacting them.) The variability among pyramidal cells appears to occur even within single classes of these cells, since in area 4 some Betz cells (layer V pyramidal cells greater than $25 \mu \mathrm{m}$ in diameter) are covered by immunoreactive terminals (Fig. 9D), while others receive none.

\section{Discussion}

The present studies demonstrate the widespread presence of tachykinin-immunoreactive neurons in the monkey cortex and the colocalization of these peptides with GABA, or with NPY and SRIF, thus extending earlier observations (Beach and McGeer, 1983; Sakamoto et al., 1985). By using antisera directed against fragments of the SP and SK molecules, we have also provided a more specific identification of the tachykinins expressed.

Two types of neurons were identified as displaying SP- and SK-like immunoreactivity. Both are clearly nonpyramidal neurons, distinguishable by their distributions and staining intensities (see also Beach and McGeer, 1983; Sakamoto et al., 1985). We found their somata to differ ultrastructurally and were able to separate them into nonoverlapping populations by the colocalization of immunoreactivity for other neuroactive substances (see below). The relatively large, intensely stained neurons are similar in morphology and distribution to cells in monkey cortex that display immunoreactivity for other neuropeptides (Hendry et al., 1984a, b; Jones and Hendry, 1986). The relatively small, lightly stained neurons have characteristics that distinguish them from the first type and from neurons displaying immunoreactivity for other known cortical neuropeptides. They are more numerous than other peptide-immunoreactive cells, and their somata are distributed most densely in the middle layers of cortex, in which other peptide-immunoreactive somata tend to be sparse.

We could see too little of the small cells' dendritic morphology
Table 1. Tachykinin-immunoreactive synapses

\begin{tabular}{llll}
$\begin{array}{l}\text { Axoso- } \\
\text { matic }\end{array}$ & $\begin{array}{l}\text { Axoden- } \\
\text { dritic }\end{array}$ & $\begin{array}{l}\text { Axo- } \\
\text { spinous }\end{array}$ & Total \\
\hline
\end{tabular}

Motor cortex (area 4) superficial layers (II-IIIB)

$\begin{array}{llrrr}\text { On pyramidal cells } & 23 & 16 & 37 & 76 \\ \text { On unidentified cells } & - & 110 & - & 110 \\ \text { TOTAL } & 23 & 126 & 37 & 186\end{array}$

Motor cortex (area 4) deep layers (V-VI)

$\begin{array}{lcrcc}\text { On pyramidal cells } & 6 & 9 & 8 & 23 \\ \text { On unidentified cells } & - & 22 & - & 22 \\ \text { Total } & 6 & 31 & 8 & 45\end{array}$

Sensory cortex (areas 1-2) superficial layers (II-III)

$\begin{array}{lcccc}\text { On pyramidal cells } & 11 & 11 & 24 & 46 \\ \text { On unidentified cells } & - & 30 & - & 30 \\ \text { Total } & 11 & 41 & 24 & 76\end{array}$

Sensory cortex (area 2) deep layers (V-VI)

$\begin{array}{lcrcc}\text { On pyramidal cells } & 3 & 3 & 4 & 10 \\ \text { On unidentified cells } & - & 18 & - & 18 \\ \text { TOTAL } & 3 & 21 & 4 & 28\end{array}$

On axon initial segments $=1$

Other synapses

Asymmetric contacts $=2$

Axosomatic (on nonpyramidal cells) $=2$

Axodendritic (on nonpyramidal cells) $=8$

TOTAL NUMBER OF BOUTONS $=312$

TOTAL NUMBER OF SYNAPSES $=348$

Distribution of 348 synaptic contacts made by 312 tachykinin-immunoreactive terminals in superficial and deep layers of motor and somatic sensory cortex, stained with antibody $\mathrm{NCl} / 34 \mathrm{HL}$. All synaptic contacts, except 2 , were clearly of the symmetric type.

to place them in a known class of cortical interneuron, but they are unlikely to be basket cells or chandelier cells, both of which are GABAergic neurons. Basket cells usually have larger somata and show much larger numbers of axosomatic terminals (DeFelipe et al., 1986) than the small tachykinin cells, and chandelier cells, though having a similar somal size, show elongated rows of synapses on pyramidal cell axon initial segments, something that is not found for tachykinin cells (DeFelipe et al., 1985).

The identified synaptic targets of tachykinin-positive neurons were mainly pyramidal neurons, although a few terminals were also identified on nonpyramidal neurons. In the present study we have found that while certain pyramidal cells receive relatively large numbers of tachykinin-positive terminals, other pyramidal cells receive very few such terminals and some receive none. The extent to which this represents a true differential distribution, an activity-dependent difference in the levels of peptide within the terminals (see Hendry et al., 1988), or simply a failure of penetration of reagents into deeper parts of a section remains to be evaluated.

\section{Neurotransmitter colocalization}

Classical amino acid or monoamine neurotransmitters and neuropeptides are found in the same populations of neurons in many parts of the CNS (Brecha, 1983; Hökfelt et al., 1984). Often the neuropeptides and the classical transmitters have been found to coexist (Hökfelt et al., 1984). In the cerebral cortex, certain GABA neurons display immunoreactivity for different neuropeptides and can, as a consequence, be divided into dif- 
ferent classes (Hendry et al., 1984b; Schmechel et al., 1984; Somogyi et al., 1984). Of the GABA/neuropeptide-positive neurons, one population expresses CCK-like immunoreactivity while a second expresses both SRIF-like and NPY-like immunoreactivities. However, the coexpression of GABA and a neuropeptide is not obligatory. The majority of GABA neurons are stained for none of these peptides (Hendry et al., 1984b; Somogyi et al., 1984), and a small proportion of cells expressing both SRIFand NPY-like immunoreactivities is not stained for the GABAsynthesizing enzyme, GAD (Hendry et al., 1984b; Schmechel et al., 1984). In the present study, 2 populations of tachykininpositive neurons were identified by patterns of colocalization. The major population of smaller, less intensely immunostained tachykinin neurons is also stained for GABA but not for SRIF and NPY. Conversely, the minor population of large tachykininpositive cells displays both SRIF- and NPY-like immunoreactivities without being stained for GABA.

GABA-like and tachykinin-like immunoreactivities coexist not only in cell bodies but also in fibers and punctate profiles. The latter were found to be synaptic terminals. The synaptic morphology and sites of termination displayed by the tachykinin-positive terminals and by GAD-positive terminals in monkey cortex (Hendry et al., 1983) are identical, suggesting that the same synaptic terminal may contain both GABA and one or more tachykinins. As with other neuropeptides, such as CCK and SRIF, that reportedly are excitatory to cortical neurons (e.g., Dodd and Kelly, 1978, 1981), SP produces an excitatory response when applied iontophoretically (Lamour et al., 1983; Jones and Olpe, 1984), while GABA is a potent inhibitory substance (Krnjević, 1974). The two might interact at a single receptor complex, but only recently have the possible actions of a neuropeptide on the GABA receptor complex been addressed (Bradwejn and de Montigny, 1984). Interactions of SP with other classical neurotransmitters in the cerebral cortex, such as acetylcholine (Lamour et al., 1983) and norepinephrine (Jones and Olpe, 1984), have also been reported. It is also possible that, by analogy with what is known of neuropeptide actions in the periphery (Jan and Jan, 1982), the tachykinins may act at sites removed from the postsynaptic GABA receptor site.

\section{Neurons of the subcortical white matter}

Previous studies of primate cerebral cortex have identified a relatively large number of SRIF- and NPY-immunoreactive cells in the white matter immediately subjacent to layer VI (Sorenson, 1982; Hendry et al., 1984b). We found some of these cells to display tachykinin-like immunoreactivity; we also found them to possess the ultrastructural features of neurons and to receive synaptic contacts along their somata and dendrites. The sources of the terminals contacting the immunoreactive neurons are not known. However, the processes of the tachykinin-positive cells themselves enter the cortex and contribute to the plexus in layer VI, indicating that these neurons are important components of cortical circuitry. They also receive very few synapses in the white matter, so their major synaptic input may occur on their processes that ascend into the cortex.

\section{Laminar and areal distribution of processes}

The plexuses of immunoreactive processes that are associated with the tachykinin-immunoreactive neurons and that at least in part arise from them adopt a similar basic pattern in the cerebral cortex. The plexuses, nonetheless, display clearly identifiable differences in density and laminar distribution from area to area. Areal differences in the density of SP fibers are most likely related to differences in SP concentration that have been detected by radioimmunoassay of monkey cortex (Hayashi and Oshima, 1986). The extent, if any, to which SP-positive afferent fibers contribute to these plexuses is not known. Although SPimmunoreactive fibers were very rarely seen in white matter at any distance from cortex, the existence of SP afferents to the cortex in rats (Cuello and Kanazawa, 1978) and the possibility that myelinated SP fibers might not be readily stained immunocytochemically could indicate that some components of the plexuses are made up of afferent axons.

\section{Tachykinins in the cerebral cortex}

Three peptides of the tachykinin family, SP, SK, and neuromedin $\mathrm{K}$, are currently recognized in the mammalian central nervous system (see Maggio, 1985, for a review). They and other tachykinins isolated from amphibian skin possess carboxyl terminal sequences that vary by no more than a single amino acid. Because of this sequence homology, previous studies (Beach and McGeer, 1983; Jones and Hendry, 1985; Sakamoto et al., 1985; Penny et al., 1986) that have relied upon antibodies against the carboxyl terminus of SP to localize this peptide in the cerebral cortex have potentially localized all tachykinins. The present data suggest that both SP-like and SK-like immunoreactivities exist within monkey cortex and that each exists within neurons intrinsic to the cortex; the data do not rule out the possibility that other tachykinins may also be present. Neuromedin $\mathrm{K}$, for example, is reported to be the most abundant tachykinin in rat cortex (Kanazawa et al., 1984). Some immunoreactive material may also represent a molecule, as yet uncharacterized, that possesses an amino acid sequence similar to that of the tachykinins.

Isolation and characterization of the preprotachykinin mRNA in bovine brain reveals that a single gene encodes for both SP and SK (Nawa et al., 1983) but that alternative splicing can produce 2 distinct $m$ RNAs, one encoding for both SP and SK and the other for SP only (Nawa et al., 1984). While it is likely that a neuron synthesizing one peptide will synthesize both (Maggio, 1985), differential posttranslational processing might lead to a failure of processing of one. Identical populations of cortical neurons were found to display SP-like and SK-like immunoreactivities, and the 2 peptides could be colocalized within the same neuron. These data are consistent with the findings of previous studies showing similar concentrations of the 2 peptides in various regions of the brain and spinal cord (Kanazawa et al., 1984) and similar changes in concentration following surgical or chemical manipulations (Maggio and Hunter, 1984; Lee et al., 1986). Hence, as at other CNS sites (Kalivas et al., 1985), SP and SK are probably both expressed by the same cell population.

High-affinity tachykinin binding sites have been localized autoradiographically and biochemically and have been interpreted as specific receptor sites (Mantyh et al., 1984a, b). In agreement with pharmacological studies, the distribution of binding sites indicates that separate and distinct receptors for various tachykinins exist in the CNS (see Maggio, 1985). Within the cerebral cortex of rats, differences between receptor types and their laminar positions are obvious, with binding sites for radiolabeled SK being dense in layers IV and V and sparse in layer I, and SP receptors displaying the opposite pattern (Mantyh et al., $1984 a, b)$. It is not known if similar differences exist in receptor localization in monkey cortex, but the distributions of neurons and processes displaying SP-like and SK-like immunoreactivity 
do not appear to differ within monkey cortex. We are currently investigating high-affinity tachykinin binding sites in the monkey cortex to determine the degree of correlation between immunoreactive neurons and processes and the distribution of their receptors.

\section{References}

Beach, T. G., and E. G. McGeer (1983) Neocortical substance P neurons in the baboon: An immunohistochemical finding. Neurosci. Lett. 41: $265-270$.

Bradwejn, J., and C. de Montigny (1984) Benzodiazepines antagonize cholecystokinin-induced activation of rat hippocampal neurones. Nalure 312: 363-364.

Brecha, N. (1983) Retinal neurotransmitters: Histochemical and biochemical studies. In Chemical Neuroanatomy, P. C. Emson, ed., pp. 85-129, Raven, New York.

Brownstein, M. J., E. A. Mroz, J. S. Kizer, M. Palkovits, and S. E. Leeman (1976) Regional distribution of substance $P$ in the brain of the rat. Brain Res. 116: 299-305.

Cuello, A. C., and I. Kanazawa (1978) The distribution of substance $P$ immunoreactive fibers in the rat central nervous system. J. Comp. Neurol. 178: 129-156.

Cuello, A. C., G. Galfré, and C. Milstein (1979) Detection of substance $P$ in the central nervous system by a monoclonal antibody. Proc. Natl. Acad. Sci. USA 76: 3532-3536.

DeFelipe, J., and A. Fairén (1982) A type of basket cell in superficial layers of the cat visual cortex. A Golgi-electron microscope study. Brain Res. 244: 9-16.

DeFelipe, J., S. H. C. Hendry, E. G. Jones, and D. Schmechel (1985) Variability in the terminations of GABAergic chandelier cell axons on initial segments of pyramidal cell axons in the monkey sensorymotor cortex. J. Comp. Neurol. 231: 364-384.

DeFelipe, J., S. H. C. Hendry, and E. G. Jones (1986) A correlative electron microscopic study of basket cells and large GABAergic neurons in the monkey sensory-motor cortex. Neuroscience 17: 9911009.

Dodd, J., and J. S. Kelly (1978) Is somatostatin an excitatory transmitter in the hippocampus? Nature 273: 674-675.

Dodd, J., and J. S. Kelly (1981) The actions of cholecystokinin and related peptides on neurons of the mammalian hippocampus. Brain Res. 205: 337-350.

Hayashi, M., and K. Oshima (1986) Neuropeptides in cerebral cortex of macaque monkey (Macaca fuscata fuscata): Regional distribution and ontogeny. Brain Res. 364: 360-368.

Hendry, S. H. C., C. R. Houser, E. G. Jones, and J. E. Vaughn (1983) Synaptic organization of immunocytochemically identified GABA neurons in the monkey sensory-motor cortex. J. Neurocytol. 12:639660.

Hendry, S. H. C., E. G. Iones, and P. C. Emson (1984a) Morphology, distribution and synaptic relations of somatostatin- and neuropeptide $\mathrm{Y}$-immunoreactive neurons in rat and monkey neocortex. J. Neurosci. 4: 2497-2517.

Hendry, S. H. C., E. G. Jones, J. DeFelipe, D. E. Schmechel, C. Brandon, and P. C. Emson (1984b) Neuropeptide-containing neurons of the cerebral cortex are also GABAergic. Proc. Natl. Acad. Sci. USA 81 . 6526-6530.

Hendry, S. H. C., H. D. Schwark, E. G. Jones, and Y. Jan (1987) Numbers and proportions of GABA-immunoreactive neurons in different areas of monkey cerebral cortex. J. Neurosci. 7: 1503-1519.

Hendry, S. H. C., E. G. Jones, and N. Burstein (1988) Activity-dependent regulation of tachykinin-like immunoreactivity in neurons of monkey visual cortex. J. Neurosci. 8: 1125-1238.

Hökfelt, T., O. Johansson, and M. Goldstein (1984) Chemical anatomy of the brain. Science 225: 1326-1334.

Hsu, S. M., L. Raine, and H. Fanger (1981) Use of avidin-biotinperoxidase complex $(\mathrm{ABC})$ in immunperoxidase techniques: $\mathrm{A}$ com parison between $\mathrm{ABC}$ and unlabeled antibody (PAP) procedures. J. Histochem. Cytochem. 29: 577-580.

Inagaki, S., M. Sakanaka, S. Shiosaka, E. Senba, L. Takatsuki, H. Takagi, Y. Kawai, H. Minagawa, and M. Tohyama (1982) Ontogeny of substance P-containing neuron systems of the rat: Immunohistochemical analysis $-I$. Forebrain and upper brain stem. Neuroscience 7: $251-273$.
Jan, Y. N., and L. Y. Jan (1982) Peptidergic transmission in sympathetic ganglia of the frog. J. Physiol. (Lond.) 327: 219-246.

Jones, E. G., and S. H. C. Hendry (1985) GABAergic, substance P-immunoreactive neurons in monkey cerebral cortex. Soc. Neurosci. Abstr. 11: 145.

Jones, E. G., and S. H. C. Hendry (1986) Peptide-containing neurons of the primate cerebral cortex. In Neuropeptides in Neurological and Psychiatric Disease, J. B. Martin and J. D. Barchas, eds., pp. 163178, Raven, New York.

Jones, E. G., S. H. C. Hendry, and J. DeFelipe (1987) Regulation of substance P immunoreactivity in GABA neurons of monkey visual cortex by sensory deprivation. In Substance $P$ and Tachykinins, J. L. Henry, ed., Springer, New York.

Jones, R. S. G., and H.-R. Olpe (1984) Activation of the noradrenergic projection from locus coeruleus reduces the excitatory responses of anterior cingulate cortical neurones to substance P. Neuroscience 13: 819-825.

Kalivas, P. W., A. Y. Deutch, J. E. Maggio, P. W. Mantyh, and R. H. Roth (1985) Substance K and substance $P$ in the ventral tegmental area. Neurosci. Lett. 57: 241-246.

Kanazawa, I., and T. Jessell (1976) Postmortem changes and regional distribution of substance $\mathrm{P}$ in the rat and mouse nervous system. Brain Res. 117: 362-367.

Kanazawa, I., T. Ogawa, S. Kimura, and E. Munekata (1984) Regional distribution of substance $P$, neurokinin alpha and neurokinin beta in rat central nervous system. Neurosci. Res. 2: 111-120.

Krnjević, K. (1974) Chemical nature of synaptic transmission in vertebrates. J. Physiol. (Lond.) 54: 318-450.

Lamiour, Y., P. Dutar, and A. Jobert (1983) Effects of neuropeptides on rat cortical neurons: Laminar distribution and interaction with the effect of acetylcholine. Neuroscience 10: 107-117.

Lee, J.-M., S. McLean, J. E. Maggio, N. Zamir, R. H. Roth, R. L. Eskay, and M. J. Bannon (1986) The localization and characterization of substance $P$ and substance $\mathrm{K}$ in striatonigral neurons. Brain Res. 371 : $152-154$

Ljungdahl, A., T. Hökfelt, and G. Nilsson (1978) Distribution of substance P-like immunoreactivity in the central nervous system of the rat. I. Cell bodies and nerve terminals. Neuroscience 3: 861-943.

Loesche, J. R., J. F. McGinty, and J.-S. Hong (1985) Cerebral cortical neurons of developing and adult rats contain the tachykinins, substance $\mathrm{P}$ and substance K. Soc. Neurosci. Abstr. 11: 90.

Maggio, J. E. (1985) "Kassinin" in mammals: The newest tachykinins. Peplides (Suppl. 3) 6: 237-243.

Maggio, J. E., and J. C. Hunter (1984) Regional distribution of kassinin-like immunoreactivity in rat central and peripheral tissues and the effect of capsaicin. Brain Res. 307: 370-373.

Mantyh, P. W., and S. P. Hunt (1986) Changes in ${ }^{3} \mathrm{H}$-substance P receptor binding in the rat brain after kainic acid lesion of the corpus striatum. J. Neurosci. 6: 1537-1544.

Mantyh, P. W., S. P. Hunt, and J. E. Maggio (1984a) Substance P receptors: Localization by light microscopic autoradiography using ${ }^{3} \mathrm{H}-\mathrm{SP}$ as the radioligand. Brain Res. 307: 147-166.

Mantyh, P. W., J. E. Maggio, and S. P. Hunt (1984b) The autoradiographic distribution of kassinin and substance $\mathrm{K}$ binding sites is different from the distribution of substance $P$ binding sites in rat brain. Eur. J. Pharmacol. 102: 361-364.

Nawa, H., T. Hirose, H. Takashima, S. Inayaka, and S. Nakanishi (1983) Nucleotide sequences of cloned cDNAs for two types of bovine brain substance $P$ precursor. Nature 306: 32-36.

Nawa, H., H. Kotani, and S. Nakanishi (1984) Tissue-specific generation of two preprotachykinin mRNAs from one gene by alternate splicing. Nature 312: 729-734.

Paxinos, G., P. C. Emson, and A. C. Cuello (1978) The substance P projections to the frontal cortex and substantia nigra. Neurosci. Lett. 7: $127-131$.

Penny, G. R., S. Afsharpour and S. T. Kitai (1986) Substance P-immunoreactive neurons in the neocortex of the rat: Subset of the glutamic acid decarboxylase-immunoreactive neurons. Neurosci. Lett. 65: 53-59.

Reynolds, E.S. (1963) The use of lead citrate at high pH as an electronopaque stain in electron microscopy. J. Cell Biol. 17: 208-212.

Sakamoto, N., K. Takatsuji, S. Shiosaka, and M. Tohyama (1985) Evidence for the existence of substance P-like immunoreactive neurons in the human cerebral cortex: An immunohistochemical analysis. Brain Res. 325: 322-324. 
Sakanaka, M., S. Shiosaka, K. Takatsuki, and M. Tohyama (1983) Evidence for the cxistence of a substance P-containing pathway from the nucleus laterodorsalis tegmenti (Castaldi) to the medial frontal cortex of the rat. Brain Res. 259: 123-126.

Schmechel, D. E., B. G. Vickrey, D. Fitzpatrick, and R. P. Elde (1984) GABAergic neurons of mammalian cerebral cortex: Widespread subclass defined by somatostatin content. Neurosci. Lett. 47: 227-232.

Somogyi, P., A. J. Hodgson, A. D. Smith, M. G. Nunzi, A. Gorio, and J.-Y. Wu (1984) Different populations of GABAergic neurons in the visual cortex and hippocampus of cat contain somatostatin- or cholecystokinin-immunoreactive material. J. Neurosci. 4: 2590-2603. Sorenson, K. V. (1982) Somatostatin: Localization and distribution in the cortex and subcortical white matter of human brain. Neuroscience $7: 1227-1232$.

Sternberger, L. A. (1979) Immunocytochemistry, 2nd Ed., Wiley, New York.

Sundler, F., E. Brodin, E. Ekblad, R. Hakanson, and R. Uddman (1985) Sensory nerve tibers: Distribution of substance $\mathrm{P}$, neurokinin $\mathrm{A}$ and calcitonin-gene-related peptide. In Tachykinin Antagonists, R. Hakanson and F. Sundler, eds., pp. 3-15, Elsevier, Amsterdam. 